\title{
High-precision ID-TIMS cassiterite U-Pb systematics using a low-contamination hydrothermal decomposition: implications for LA-ICP-MS and ore deposit geochronology
}

\author{
Simon Tapster ${ }^{1}$ and Joshua W. G. Bright ${ }^{1,2}$ \\ ${ }^{1}$ Geochronology and Tracers Facility, British Geological Survey, Keyworth, Nottinghamshire, NG12 5GG, UK \\ ${ }^{2}$ Department of Chemistry, University of Surrey, Guildford, GU2 7XH, UK
}

Correspondence: Simon Tapster (simont@bgs.ac.uk)

Received: 19 December 2019 - Discussion started: 16 January 2020

Revised: 1 June 2020 - Accepted: 8 July 2020 - Published: 18 December 2020

Abstract. Cassiterite $\left(\mathrm{SnO}_{2}\right)$ is the most common ore phase of Sn. Typically containing $1-100 \mu \mathrm{gg}^{-1}$ of uranium and relatively low concentrations of common $\mathrm{Pb}$, cassiterite has been increasingly targeted for $\mathrm{U}-\mathrm{Pb}$ geochronology, principally via microbeam methods, to understand the timing and durations of granite-related magmatic-hydrothermal systems throughout geological time. However, due to the extreme resistance of cassiterite to most forms of acid digestion, there has been no published method permitting the complete, closed-system decomposition of cassiterite under conditions in which the basic necessities of measurement by isotope dilution can be met, leading to a paucity of reference and validation materials. To address this a new low blank $(<1 \mathrm{pg} \mathrm{Pb})$ method for the complete acid decomposition of cassiterite utilising $\mathrm{HBr}$ in the presence of a mixed $\mathrm{U}-\mathrm{Pb}$ tracer, $\mathrm{U}$ and $\mathrm{Pb}$ purification, and thermal ionisation mass spectrometry (TIMS) analyses has been developed. Decomposition rates have been experimentally evaluated under a range of conditions. A careful balance of time and temperature is required due to competing effects (e.g. HBr oxidation), yet the decomposition of $500 \mu \mathrm{m}$ diameter fragments of cassiterite is readily achievable over periods comparable to zircon decomposition. Its acid-resistant nature can be turned into an advantage by leaching common Pb-bearing phases (e.g. sulfides, silicates) without disturbing the U-Pb systematics of the cassiterite lattice. The archetypal Sn-W greisen deposit of Cligga Head, SW England, is used to define accuracy relative to chemical abrasion-isotope dilution-thermal ionisation mass spectrometry (CA-ID-TIMS) zircon U-Pb ages and demonstrates the potential of this new method for resolving high- resolution timescales $(<0.1 \%)$ of magmatic-hydrothermal systems. However, data also indicate that the isotopic composition of initial common $\mathrm{Pb}$ varies significantly, both between crystals and within a single crystal. This is attributed to significant fluid-rock interactions and the highly F-rich acidic nature of the hydrothermal system. At microbeam precision levels, this issue is largely unresolvable and can result in significant inaccuracy in interpreted ages. The ID-TIMS $\mathrm{U}-\mathrm{Pb}$ method described herein can, for the first time, be used to properly characterise suitable reference materials for microbeam cassiterite $\mathrm{U}-\mathrm{Pb}$ analyses, thus improving the accuracy of the $\mathrm{U}-\mathrm{Pb}$ cassiterite chronometer as a whole.

\section{Introduction}

Cassiterite $\left(\mathrm{SnO}_{2}\right)$ is the primary tin ore, precipitated from magmatic-hydrothermal fluids exsolved in association with reduced granitic systems and pegmatite bodies. The mineral systems that contain cassiterite are globally distributed, and they span the majority of geological time from the Archean to the Neogene (Kesler and Wilkinson, 2015). Cassiterite commonly contains 1 to $100 \mu \mathrm{gg}^{-1}$ of uranium and has the potential to contain relatively low levels of common $\mathrm{Pb}$ (e.g. Li et al., 2016; Moscati and Neymark, 2019; Neymark et al., 2018). The potential of cassiterite as a U-Pb geochronometer to understand the timing of magmatic-hydrothermal Sn deposits, and their many associated elements critical for modern technology, e.g. Li, W, Nb and Ta, has long been recognised since the first reported isotope dilution-thermal ionisation mass spectrometry (ID-TIMS) U-Pb analyses (Gulson 
and Jones, 1992). Research into cassiterite U-Pb geochronology paused for some time due to the questionable accuracy of the first published results (McNaughton et al., 1993) and the difficulty in the hydrothermal decomposition of cassiterite required for isotope dilution methods due to the extremely acid-resistant nature of cassiterite (Gulson and Jones, 1992; Neymark et al., 2018). With the advent of microbeam techniques, cassiterite $\mathrm{U}-\mathrm{Pb}$ geochronology has now become widely accessible. Techniques such as laser ablation inductively coupled mass spectrometry (LA-ICP-MS) and ion microprobe (Carr et al., 2017) offer a rapid solution to analysing the $\mathrm{U}-\mathrm{Pb}$ systematics of cassiterite without the direct need for dissolving a sample. With analytical precision of $\sim 1 \%-$ $2 \% 2 \sigma$ and a current total uncertainty limit of $\sim 2 \%$ based upon long-term reproducibility and inter-laboratory comparison of zircon U-Pb analyses (Horstwood et al., 2016), LAICP-MS U-Pb techniques offer the capability to provide chronology that may address issues such as the timing of ore deposition at broad, regional scales. Issues specific to cassiterite LA-ICP-MS U-Pb analyses are outlined below. Higher-temporal-resolution questions, such as those that begin to address processes on magmatic timescales, require a refinement of these uncertainties. For microbeam techniques this may result from the refined standardisation of the methodology and identification of systematic uncertainties identified over long-term analysis using well-characterised reference materials (RMs)(Horstwood et al., 2016).

The accuracy of $\mathrm{U}-\mathrm{Pb}$ microbeam geochronology requires that effects such as matrix interaction with analyte ion beams and "down-hole" inter-element fractionation be corrected for. This is commonly negated by using RMs with an equivalent chemistry and ablation (or sputtering) characteristics (i.e. a matrix-matched RM). Samples of unknown isotopic composition are measured relative to well-characterised RMs that are relatively homogenous at the scale of the spatial resolution and at the precision of the analyses typically characterised by ID-TIMS U-Pb analyses.

Thus far, a fundamental issue for cassiterite $\mathrm{U}-\mathrm{Pb}$ geochronology has arisen from the challenges of achieving the total decomposition of cassiterite in a single closedsystem step, which is required for the effective quantitative $\mathrm{U} / \mathrm{Pb}$ determination of the material by isotope dilution methods. Previous ID-TIMS U-Pb studies (Gulson and Jones, 1992; Rizvanova et al., 2017; Yuan et al., 2008) utilising concentrated $\mathrm{HCl}$ required stepwise decomposition and acid recharges that still only achieved partial decompositions in many instances. These studies also required the postdecomposition addition of isotopic U-Pb tracers. This approach will likely preserve the $\mathrm{Pb}$ isotope systematics of the sample; for cassiterite this will represent a mixture of common $\mathrm{Pb}(\mathrm{Pbc})$ components and radiogenic $\mathrm{Pb}\left(\mathrm{Pb}^{*}\right)$. However, it introduces a high potential to fractionate the $\mathrm{U}-\mathrm{Pb}$ inter-element ratios, either due to the incongruous dissolution of $\mathrm{U}$ and $\mathrm{Pb}$, and different elemental behaviours before equilibrium with the tracer is achieved. These issues will in turn affect the integrity of $\mathrm{U}-\mathrm{Pb}$-derived dates and therefore the interpretation of $\mathrm{Pb}$ loss or $\mathrm{Pbc}-\mathrm{Pb}^{*}$ mixing trajectories that require assumptions about concordance of the $\mathrm{U}-\mathrm{Pb}$ chronometers. As noted by Neymark et al. (2018) these effects lead to reverse discordance (U loss or $\mathrm{Pb}$ gain) between the resulting cassiterite analyses. Whilst this effect can be easily detected in older cassiterite data wherein trajectories approach being perpendicular to concordia, within younger samples, fractionation will merely drive samples nearly parallel to the line of concordia, making it difficult to distinguish from real age variations.

Many previous microbeam cassiterite $\mathrm{U}-\mathrm{Pb}$ studies have used some combination of zircon RM or glass RM, with a "matrix-matched" cassiterite RM that has had isotopic ratios characterised by ID-TIMS following a stepwise decomposition (e.g. Yuan et al., 2011, 2008; Zhang et al., 2017; Li et al., 2016; Liu et al., 2007). The reference values have the potential to have been effected by the issues described above, with inaccuracies propagating into the resulting in situ ages.

Neymark et al. (2018) developed an approach that utilised the highly repeatable ablation characteristics of cassiterites to overcome the matrix-matching issues in microbeam analysis that stem from the absence of well-characterised cassiterite material that can be used as an RM. to The matrix biases relative to a NIST glass primary RM were normalised by deriving a "fractionation factor" for each analytical session. This was achieved by measuring the offset between the lower intercept age on a Tera-Wasserburg (T-W) plot and an assumed "true" age defined by the $\mathrm{Pb}-\mathrm{Pb}$ isochron that was shown to be in good agreement with independent chronological constraints for the Proterozoic "SPG" cassiterite. The application of this approach to a wide range of materials across geological time, and the general agreement with independent geological and temporal constraints of their associated systems (Moscati and Neymark, 2019; Neymark et al., 2018), indicates that this approach was versatile and can be reliably applied to constrain the general timing of ore deposits. However, without characterising the U-Pb systematics of cassiterite materials by precise methods the potential level of accuracy in resulting geological interpretations is difficult to assess.

Regardless of the microbeam approach adopted, it is crucial that the session and long-term accuracy and dispersion of any $\mathrm{U}-\mathrm{Pb}$ analytical approach can also be validated by the analysis of independently well-characterised cassiterites (i.e. secondary and tertiary RMs) (e.g. Horstwood et al., 2016). The motivation for developing a method for cassiterite ID-TIMS U-Pb geochronology that involves the total decomposition of cassiterite in the presence of, and achieving equilibrium with, a $\mathrm{U}-\mathrm{Pb}$ isotope tracer is to provide a means to characterise cassiterite materials to assess accuracy and a means to examine magmatic-hydrothermal timescales within cassiterite-bearing deposits beyond the consensus ca. $2 \%$ absolute uncertainty that is permitted by microbeam $\mathrm{U}_{-}$ $\mathrm{Pb}$ methods (e.g. Horstwood, 2016). 
Desirable characteristics of a method are also the following: (1) contribution of low amounts of $\mathrm{Pbc}$ to the sample during decomposition and chemical separation using reagents that can be easily handled and distilled; (2) the method can achieve decomposition on timescales that are easily operable for the laboratory environment, e.g. zircon decomposition is typically achieved within $\sim 72 \mathrm{~h}$; and (3) the method utilises geologically meaningful amounts of material capable of resolving spatial variations in isotopic ratios. This study demonstrates the potential of cassiterite decomposition with concentrated $\mathrm{HBr}$ to fulfil the necessary criteria for routine ID-TIMS cassiterite $\mathrm{U}-\mathrm{Pb}$ geochronology. We provide preliminary data for two cassiterite materials that have the potential for use as RMs, and we evaluate the accuracy of cassiterite $\mathrm{U}-\mathrm{Pb}$ geochronology using the case study of the classic W-Sn magmatic hydrothermal system of Cligga Head, SW England, which illustrates the complexities and biases that may arise for cassiterite $\mathrm{U}-\mathrm{Pb}$ geochronology.

Cassiterite is notoriously resistant to decomposition in acids (Mathur et al., 2017; Yamazaki et al., 2013). Although analysis of Sn isotopes within cassiterite is well-established, decomposition has typically been conducted by alkali fusion (Hall, 1980; Sear, 1997), reduction with graphite (Clayton et al., 2002; Hall, 1980) or potassium cyanide reduction (Haustein et al., 2010; Mathur et al., 2017). These methods require high temperatures $\left(800-1200^{\circ} \mathrm{C}\right.$ ) and open systems, making them inappropriate for ID U-Pb geochronology. Hydroiodic acid has been demonstrated as an effective means of cassiterite decomposition at relatively low temperatures $100{ }^{\circ} \mathrm{C}$ (Caley, 1932). More recent work was able to dissolve $1 \mathrm{mg}$ of cassiterite in high-pressure decomposition vessels at $100^{\circ} \mathrm{C}$ over four sequences of $24 \mathrm{~h}$, exchanging the acid at each step (Yamazki et al., 2013; Mathur et al., 2017). Despite the potential of HI as a means to decompose cassiterite, there are several drawbacks as HI readily reacts with oxygen within air requiring refrigerated storage, is less readily available with certification to $<1 \mathrm{pg} \mathrm{mL}^{-1}$ of $\mathrm{Pb}$, and is significantly more expensive when compared with $\mathrm{HBr}$. Similarly, the decomposition procedure of Yamazki et al. (2013) yielded a $1 \mathrm{ng}$ Sn blank, and whilst it is conjecture to predict the associated Pbc blank, if on this order of magnitude it would rule out $\mathrm{HI}$ as a low-contamination method for high-precision geochronology of cassiterite. Upon drying of the dissolved samples Yamazki et al. (2013) noted the formation of precipitates which were insoluble with a range of acids $\left(\mathrm{HCl}, \mathrm{HF}, \mathrm{HClO}_{3}, \mathrm{HNO}_{3}\right)$; it is possible that these could also sequester $\mathrm{Pb}$ and $\mathrm{U}$, significantly decreasing recoveries. Previous efforts to analyse cassiterite $\mathrm{U}-\mathrm{Pb}$ through ID methods for geochronology have utilised a concentrated HCl-based decomposition within high-pressure acid digestion vessels (Gulson and Jones, 1992; Liu et al., 2007; Yuan et al., 2008, 2011; Rizvanova et al., 2017). The previously reported contributions of $\mathrm{Pbc}$ from the method have been on the order of $0.2-0.3 \mathrm{ng}$ (Gulson and Jones, 1992) to $0.8 \mathrm{ng}$
(Yuan et al., 2011, 2008), many orders of magnitude greater than what is typically achieved by modern zircon chemical abrasion-isotope dilution-thermal ionisation mass spectrometry (CA-ID-TIMS) geochronology methods $(<0.5 \mathrm{pg})$. The issues of incomplete decomposition in previous studies was highlighted by Neymark et al. (2018). Although not explicit about the number of fractions that did not dissolve, the methods of Yuan et al. (2008) indicated that at least some of their cassiterite was not decomposed after $72 \mathrm{~h}$ in $12 \mathrm{M} \mathrm{HCl}$ at $205^{\circ} \mathrm{C}$ in high-pressure digestion vessels and required multiple acid exchange steps as well as also further crushing with a pestle and mortar between decomposition steps. Gulson and Jones (1992) also utilised a $48-72 \mathrm{~h}, \sim 200^{\circ} \mathrm{C}, 12 \mathrm{M} \mathrm{HCl}$ decomposition stage within a high-pressure digestion vessel and noted that in some instances for $\sim 200 \mathrm{Ma}$ cassiterite, $<5 \%$ of cassiterite was dissolved after numerous steps. The potential for inaccuracy in cassiterite $\mathrm{U}-\mathrm{Pb}$ geochronology was illustrated by Gulson and Jones (1992), who presented a very precise age $( \pm \sim 0.1 \% 2 \sigma)$ from a discordia regression line with an upper intercept age of 2098.6 Ma $\pm 3.1 \mathrm{Ma}$ for cassiterite associated with granitic rocks within the Bushveld Complex, South Africa. This cassiterite age was quickly challenged at the time on account of the much younger zircon ages of the associated granites (McNaughton et al., 1993). Extensive high-precision CA-ID-TIMS zircon U-Pb geochronology of the relatively older Rustenberg layered igneous suite of the Bushveld Complex (Mungall et al., 2016; Scoates and Friedman, 2008; Scoates and Wall, 2015; Zeh et al., 2015) has now confidently demonstrated that the cassiterite age is at least $>40 \mathrm{Myr}(>2 \%)$ too old. The potential to decompose tin oxides at pressure using $9 \mathrm{M}(48 \%)$ $\mathrm{HBr}$ in high-pressure digestion vessels has been identified for some time now (Doležal et al., 1969), yet its application has been somewhat overlooked for U-Pb geochronology despite its strong acidic, reducing nature that is comparable to HI.

\section{Controls on the timescales of cassiterite hydrothermal decomposition with $9 \mathrm{M} \mathrm{HBr}$}

The ability of $9 \mathrm{M} \mathrm{HBr}$ to decompose cassiterite over a range of temperatures and grain sizes was investigated in a series of step-leaching experiments. Timescales were assessed for two different cassiterite crystal samples (Fig. 1): (1) "Casnig" with an age of $\sim 150 \mathrm{Ma}$ and a heavily quenched cathodoluminescence $(\mathrm{CL})$ response, indicating a high concentration of Fe (Farmer et al., 1991); (2) a single $\sim 1 \mathrm{~cm}$ diameter cassiterite from the Permian Cligga Head, SW England, which demonstrates strong zonation under CL. Around 0.015 to $0.03 \mathrm{~g}$ of cassiterite fragments, both powdered in a pestle and mortar to $<10$ to $50 \mu \mathrm{m}$ and as coarse $500 \mu \mathrm{m}$ length cubes, was decomposed in a $50 \times$ molar excess of $9 \mathrm{M} \mathrm{HBr}$ in Savillex high-pressure digestion vessels (Parr Bombs) at a range of temperatures $\left(180-230^{\circ} \mathrm{C}\right)$. Decomposition steps lasted 

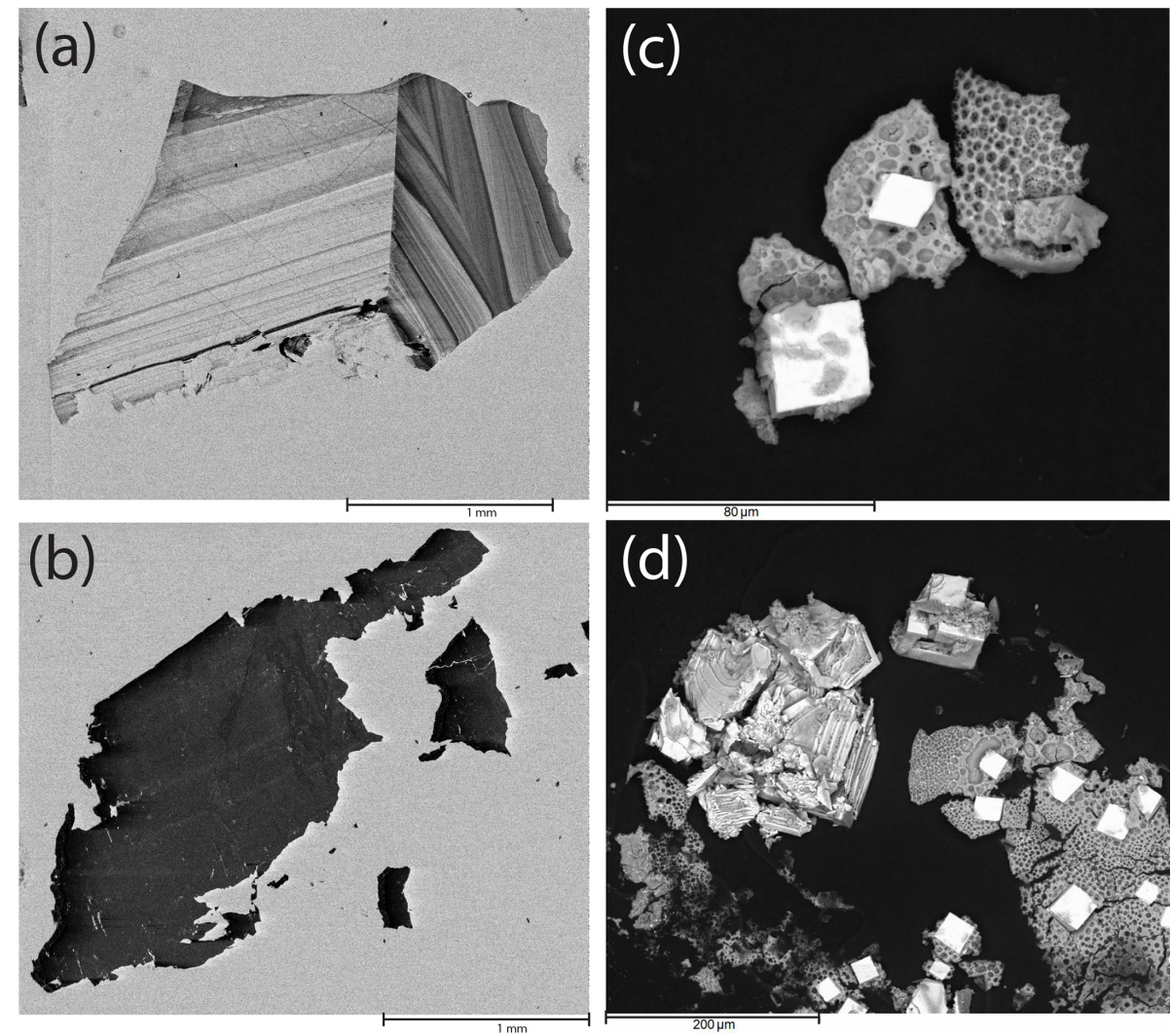

Figure 1. (a) Representative CL image of cassiterite from Cligga Head used for decomposition experiments and geochronology. (b) Representative CL image of the Casnig cassiterite used for decomposition experiments. (c, d) SEM images of the precipitate formed after drying down the $\mathrm{HBr}$ leachate after cassiterite decomposition. Light-coloured crystals are tin bromide crystals; the "spongy" texture contains bromides of $\mathrm{Fe}, \mathrm{Nb}$ and $\mathrm{Ti}$.

for $12 \mathrm{~h}$ or $96 \mathrm{~h}$, and the mass decrease in the residual cassiterite was documented (see the Supplement for full data), following extraction and extensive rinsing of the leachate. The acid was recharged and the experiment repeated. Complexity in the weighing arose from $\mathrm{Br}_{2}$ released during the decomposition steps, diffusing into the perfluoroalkoxy alkane (PFA) vessels and thus increasing the mass. The mass would then decrease as $\mathrm{Br}_{2}$ diffused out of the PFA vessel during hotplate dry-down steps $\left(120^{\circ} \mathrm{C}\right)$ before weighing. Experimental runs of PFA vessels without cassiterite present indicated the potential mass variation at each weighing stage to be $\pm 0.00154 \mathrm{~g}(2 s)$. Scanning electron microscope imagery and energy-dispersive spectroscopy of the precipitated leachate after a decomposition step identified crystalline tin bromide salts and spongy-textured $\mathrm{Ti}, \mathrm{Nb}$ and $\mathrm{Fe}$ bromides which reflect minor elements contained within the cassiterite (Fig. 1). No tin oxide was identified, supporting the idea that the mass reduction at each stage was due to the decomposition of cassiterite in $\mathrm{HBr}$.

Decomposition experiments run at 180 and $200^{\circ} \mathrm{C}$ did not exhibit a significant reduction in mass beyond the mass variation in the beaker due to $\mathrm{Br}_{2}$ diffusion. No clear temperature control was exerted between 210 and $230^{\circ} \mathrm{C}$, and most experiments demonstrated a relatively large variation in the amount dissolved over $12 \mathrm{~h}$ from step to step. Likewise, there was no consistent variation in the amount decomposed over $12 \mathrm{~h}$ between the two different starting materials of cassiterite at a given temperature. In general more cassiterite decomposed when powdered in a pestle and mortar than when placed in as larger fragments, although significant variation in the rate of a given step was still present. Notably there was little variation between the total mass of cassiterite decomposed in either a $96 \mathrm{~h}$ step or a $12 \mathrm{~h}$ step, indicating the majority of cassiterite decomposition occurs within the first $12 \mathrm{~h}$ or less. We suggest that this apparent decrease in rate resulted from a rapid reduction in $\mathrm{HBr}$ molarity when $\mathrm{HBr}$ was exposed to high temperatures. The strong brown discolouration and mass increase of the decomposition vessel, which was not unique to cassiterite-bearing experiments, implied that $\mathrm{Br}_{2}$ was likely generated through a reaction with atmospheric oxygen. It is well-documented that aqueous solutions of $\mathrm{HI}$ readily react with atmospheric oxygen at room temperatures to produce $\mathrm{I}_{2}$, which further reacts with $\mathrm{HI}$ to produce $\mathrm{HI}_{3}$, and a similar reaction between $\mathrm{O}_{2}$ and $\mathrm{HCl}$ occurs, just at a much slower rate (and requiring higher temperatures). It follows that this reaction occurs with $\mathrm{HBr}$, although it ap- 


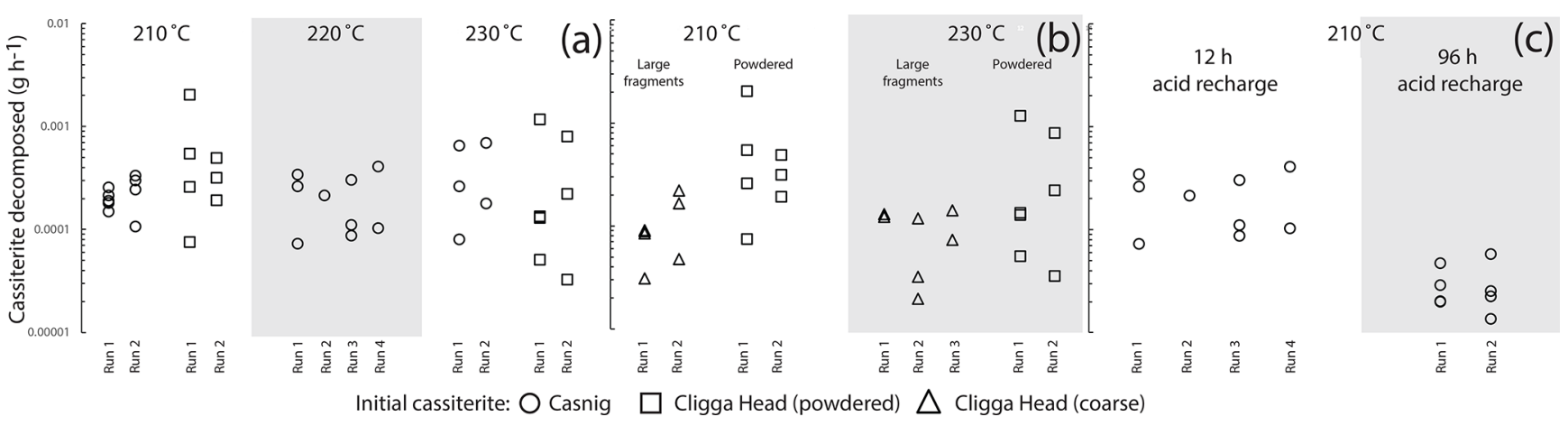

Figure 2. Plots of integrated decomposition rates for different initial cassiterite materials. Variations in mass below those induced by $\mathrm{Br}_{2}$ diffusion into the beaker are not displayed. (a) Variation in rate over a $12 \mathrm{~h}$ decomposition step at different temperatures within high-pressure vessels for powdered cassiterite. (b) Differences in rates between coarse fragments approximating cubes $500 \mu \mathrm{m}$ in length, and cassiterite powdered in a pestle and mortar at 210 and $230^{\circ} \mathrm{C}$. (c) The difference in rate averaged over 12 to $96 \mathrm{~h}$ decomposition steps at $210{ }^{\circ} \mathrm{C}$. See the text for discussion.

pears not to be previously well-documented. The decomposition experiments act as an informative guide for cassiterite decomposition, but given the scales of the experiment design required to overcome weighing issues, it is unlikely that they comprehensively reflect the rates of cassiterite decomposition in $9 \mathrm{M} \mathrm{HBr}$. Whether a cassiterite sample completely decomposes within a single step is likely to be fundamentally controlled by the surface area to volume (or mass) ratio of the cassiterite that is exposed to the acid during the earliest stages of decomposition, before the $\mathrm{HBr}$ is lost and becomes ineffective for cassiterite decomposition. Use of a significant excess of concentrated $\mathrm{HBr}$ is proposed; in the later experiments for $\mathrm{U}-\mathrm{Pb}$ geochronology a molar excess of $\sim 190$ times was used. To ensure that complete singlestep decomposition can be achieved, we advise carrying out a trial decomposition experiment to ensure that a given mass and fragment size of a specific cassiterite sample can be decomposed within the parameters of the experiment chosen.

\section{Method for cassiterite ID-TIMS U-Pb geochronology}

An overview of the methods employed and described within this section is provided in Fig. 3, in addition to petrogenetic characterisation techniques that can be employed within the workflow prior to ID-TIMS U-Pb analyses, although these have not been fully utilised within this study. The specifics of sampling style, sizes and experimental conditions are offered as guidelines. Their selection will be dependent on user requirements and the nature of the sample material.

\subsection{Sample preparation}

Fragments of cassiterite grains were crushed under acetone in a pre-cleaned agate pestle and mortar and transferred to a PFA beaker. The acetone was then evaporated and the powdered material was rinsed first in $\mathrm{H}_{2} \mathrm{O}$, then with $4 \mathrm{M} \mathrm{HNO}_{3}$ before being refluxed in aqua regia at $120^{\circ} \mathrm{C}$ overnight with the aim of dissolving sulfide and Fe oxide inclusions that were exposed within the powdered cassiterite grains (e.g. Gulson and Jones, 1992). Samples were rinsed in $4 \mathrm{MHNO}_{3}$ and $\mathrm{H}_{2} \mathrm{O}$. In the case of samples that underwent an additional step of HF leaching, samples were refluxed at $120^{\circ} \mathrm{C}$ overnight in $\sim 300-400 \mu \mathrm{L} 29 \mathrm{M} \mathrm{HF}$ and trace $\mathrm{HNO}_{3}$ on a hotplate. The leached cassiterite was then rinsed in $4 \mathrm{M} \mathrm{HNO}_{3}$ and $\mathrm{H}_{2} \mathrm{O}$. Sub-aliquots of leached cassiterite material that visually approximated the material contained in a $\sim 500 \mu \mathrm{m}$ sided cube of cassiterite were then transferred into $500 \mu \mathrm{L}$ PFA microcapsules (Parrish, 1987) that had undergone several steps of overnight cleaning in $9 \mathrm{M} \mathrm{HBr}$ within the Parr vessels, in addition to normal $\mathrm{HF}$ and $\mathrm{HCl}$ cleaning routines. Samples were briefly ( $\sim 30 \mathrm{~min}$ ) refluxed (hotplate, $120^{\circ} \mathrm{C}$ ) and rinsed in $1 \mathrm{M} \mathrm{HBr}$, leaving a minimal amount of acid in the capsule, whilst at the same time ensuring no sample material was removed before being spiked with $\sim 0.005 \mathrm{~g}$ of EARTHTIME 535 tracer (Condon et al., 2015). Approximately $450 \mu \mathrm{L}$ of $9 \mathrm{M} \mathrm{HBr}$ (Romil ultra-purity acid - UPA analysed to have $<0.04 \mathrm{pg} \mathrm{mL}^{-1}$ of $\mathrm{Pbc}$ ) was added before placing in the oven for five nights at $210{ }^{\circ} \mathrm{C}$ within a highpressure digestion vessel. Following decomposition, the solution was dried on a hotplate at $120^{\circ} \mathrm{C}$ and converted to a chloride by the addition of $400 \mu \mathrm{L}$ of $3 \mathrm{M} \mathrm{HCl}$ and placed in the oven for a further $12 \mathrm{~h}$ at $180^{\circ} \mathrm{C}$ using a high-pressure vessel.

One noteworthy observation made over the course of cleaning the PFA capsules in $9 \mathrm{M} \mathrm{HBr}$ overnight at $230^{\circ} \mathrm{C}$ was that the apparent $\mathrm{Pbc}$ was found to have doubled relative to the previous cleaning stage at $210^{\circ} \mathrm{C}$, and the equivalent amount of in-house ${ }^{208} \mathrm{~Pb}$ tracer produced very poor beam intensities. This was interpreted as a result of organic compounds released by the reaction of the $\mathrm{HBr}$ with the PFA capsule. Despite potential benefits from more rapid decomposition at $230^{\circ} \mathrm{C}$, lower temperatures are recommended. 


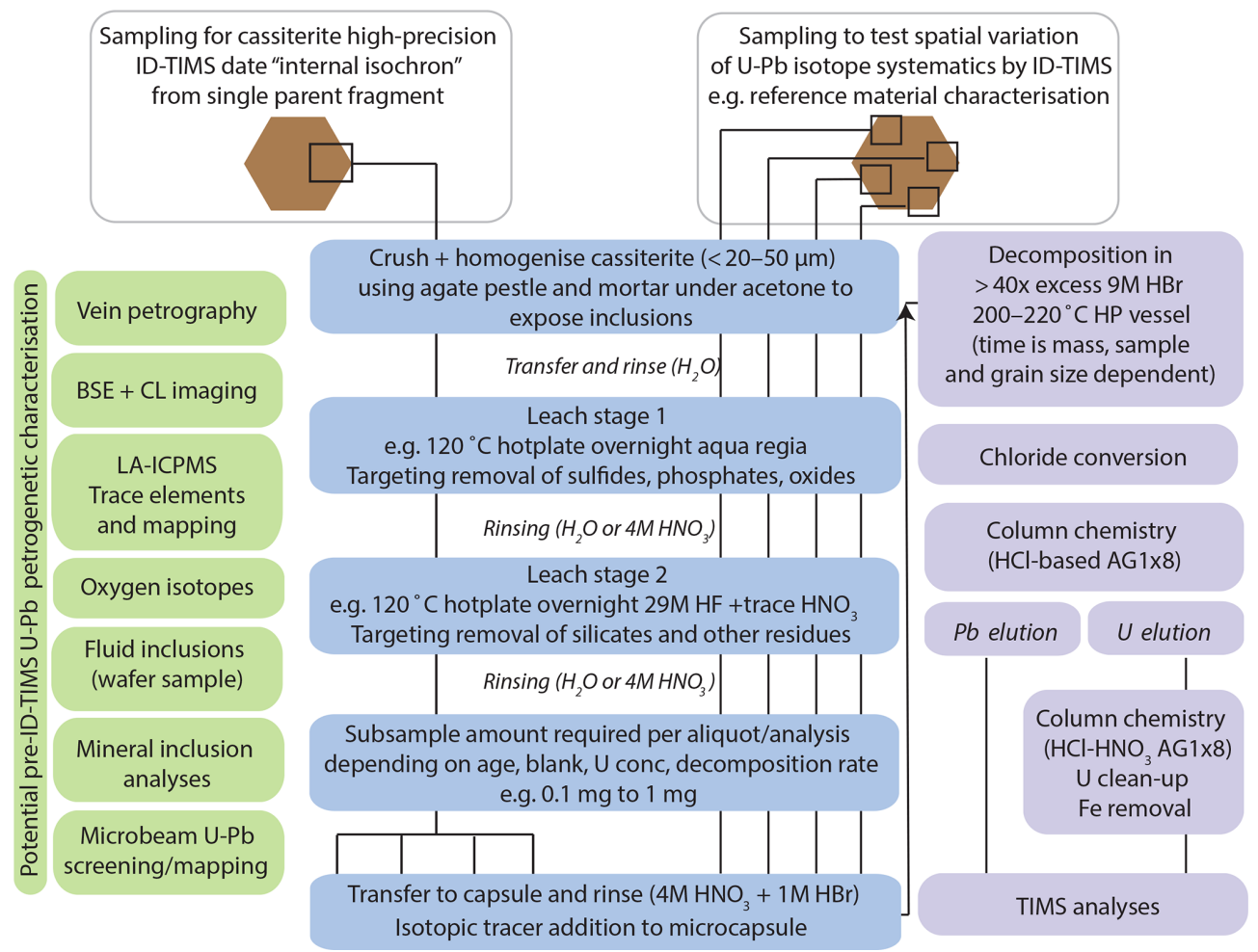

Figure 3. A generalised workflow for cassiterite ID-TIMS U-Pb geochronology. ID-TIMS analyses can be employed after the listed petrogenetic characterisation techniques on sample material. The schematic representation of sample aliquots and sub-aliquots illustrates the different approaches utilised within the study based on application (characterising heterogeneity in reference materials or internal isochron approach to avoid issues with spatial heterogeneity in Pbc composition; see Fig. 7 for further details on internal isochron formed from subaliquots). Note that many experimental variables will be sample material and user requirement dependent. For a discussion of decomposition times, see Sect. 4.

\subsection{Cassiterite $\mathrm{U}-\mathrm{Pb}$ anion exchange chromatography}

A two-stage column chemistry procedure was determined following investigations to isolate $\mathrm{Pb}$ and $\mathrm{U}$ from matrix elements using $0.05 \mathrm{~mL}$ of pre-cleaned AG 1-x8 200-400 mesh resin (BIO-RAD, CA, USA) and a homogeneous solution of dissolved cassiterite equating to a $\sim 500 \mu \mathrm{m}$ length cube grain (or $0.875 \mathrm{mg}$ at an assumed density of $\sim 7 \mathrm{~g} \mathrm{~cm}^{-3}$ ). In the first stage a modification of the $\mathrm{HCl}$-based anion exchange chromatography typically used for zircons (Krogh, 1973) was used. The sample was loaded onto the columns in $3 \mathrm{M} \mathrm{HCl}$, before further $3 \mathrm{M} \mathrm{HCl}$ being added in several stages of $30 \mu \mathrm{L}$ and then several stages of $130 \mu \mathrm{L} 3 \mathrm{M}$ $\mathrm{HCl}$. These washes contained the majority of eluted $\mathrm{Nb}, \mathrm{Ti}$ and $\mathrm{Th}$. The $\mathrm{Pb}$ was eluted in three stages of $150 \mu \mathrm{L} 6 \mathrm{M}$ $\mathrm{HCl}$, collected and dried down with $\sim 10 \mu \mathrm{L} 0.03 \mathrm{M} \mathrm{H}_{3} \mathrm{PO}_{4}$. The $\mathrm{U}$ was eluted using three steps of $150 \mu \mathrm{L}$ of $\mathrm{H}_{2} \mathrm{O}$, followed by one step of $150 \mu \mathrm{L}$ of $1 \mathrm{M} \mathrm{HCl}$. As the U fraction was found to contain almost all eluted $\mathrm{Fe}$ and $\mathrm{Sn}$, a further $\mathrm{U}$ clean-up stage was required. The U-bearing solution was dried and re-dissolved in $300 \mu \mathrm{L} 8 \mathrm{M} \mathrm{HNO}_{3}$ before being loaded onto columns, again containing $0.05 \mathrm{~mL}$ of pre-cleaned AG 1-x8 resin. Columns were washed in three stages of $350 \mu \mathrm{L} 8 \mathrm{MHNO}_{3}$, followed by two steps of $350 \mu \mathrm{L} 8 \mathrm{M} \mathrm{HCl}$. The $\mathrm{U}$ was eluted using two steps of $200 \mu \mathrm{L} 0.2 \mathrm{M} \mathrm{HCl}$, collected and dried down with $\sim 10 \mu \mathrm{L}$ $0.03 \mathrm{M} \mathrm{H}_{3} \mathrm{PO}_{4}$.

For steps after crushing in a pestle and mortar, the $\mathrm{Pbc}$ procedural blank was found to be on the order of $\sim 0.5 \mathrm{pg}$. The procedural blank will be subject to laboratory variations, and the efficacy with which any material abraded during crushing within a pestle and mortar can be removed prior to decomposition within $\mathrm{HBr}$. The effects of HF leaching prior to decomposition are evaluated below; the lowest total sample and laboratory $\mathrm{Pbc}$ of $\sim 1.5 \mathrm{pg}$, including any pestle and mortar contributions, indicates that crushing is a minor contributor to post-HF leaching. Crucially, the component of Pbc contributed by the method is 1 to 4 orders of magnitude less than the amount of $\mathrm{Pb}^{*}$ of the materials examined within this study, and the initial Pbc within the cassiterite is likely 1 or 2 orders of magnitude greater than that from the laboratory.

\subsection{Mass spectrometry and data reduction}

The $\mathrm{Pb}$ and $\mathrm{U}$ of a given sample were independently loaded on a zone-refined Re filament in $1.5 \mu \mathrm{L}$ of silica gel ma- 
trix (Gerstenberger and Haase, 1997). Isotope ratio measurements were made using a Thermo Triton TIMS at the British Geological Survey following typical methods described by Tapster et al. (2016). Raw U and Pb data were filtered using the Tripoli software programme (Bowring et al., 2011). Data reduction and uncertainty propagation used a modified Excel spreadsheet (Schmitz and Schoene, 2007) with the U decay constants of Jaffey et al. (1971), the ${ }^{238} \mathrm{U} /{ }^{235} \mathrm{U}$ ratio of Hiess et al. (2012) and the decay constants of Cheng et al. (2000) for ${ }^{230} \mathrm{Th}$. Concordia diagrams and regressions were constructed using the Excel add-in ISOPLOT 4.15 (Ludwig, 2008), and initial disequilibrium corrections utilised the IsoplotR package (Vermeesch, 2018)

\section{Cassiterite ID-TIMS U-Pb results}

\subsection{SPG-IV ad hoc RM cassiterite}

The SPG-IV cassiterite is taken from the Pitkäranta ore district, Russian Karelia, and was utilised by Neymark et al. (2018) as a cassiterite reference material for deriving the fractionation factor of analytical sessions. The age of the cassiterite based on geological constraints and zircon dating of associated magmatism was inferred to be between 1546.7 and 1537.9 Ma (Amelin et al., 1997). Neymark et al. (2018) presented an LA-ICP-MS ${ }^{207} \mathrm{~Pb}^{*} /{ }^{206} \mathrm{~Pb}^{*}$ weighted-mean date of $1542.7 \pm 1.5 \mathrm{Ma}$ and a date of $1539.8 \pm 3.5 \mathrm{Ma}$ for three partially dissolved, reversely discordant ID-TIMS analyses (N. Rizvanova, written communication, 2017, in Neymark et al., 2018).

The free regression of three tightly clustered ID-TIMS analyses (Fig. 4) of spatially independent aliquots of the SPG-IV cassiterite yields a lower intercept of $1535.9 \pm$ $5.5 \mathrm{Ma}$ (mean squared weighted deviation or MSWD =2.0). As utilised by Neymark et al. (2018) for dates that cluster close to concordia, anchoring the common $\mathrm{Pb}$ component of the T-W isochron to the mean ${ }^{207} \mathrm{~Pb} /{ }^{206} \mathrm{~Pb}$ value of 11 galena analyses from the ore system $(1.0104 \pm 0.0062)$ (Larin et al., 1990) generates a lower intercept date of $1536.6 \pm 1.0$ $(\mathrm{MSWD}=1.02)($ Fig. 4). The total Pbc amounts for these analyses range from $\sim 5$ to $15 \mathrm{pg}$, and ${ }^{206} \mathrm{~Pb} /{ }^{204} \mathrm{~Pb}$ ranges from $\sim 12000$ to $\sim 23000$.

Comparison of the ID-TIMS T-W lower intercept dates with the LA-ICP-MS Pb-Pb isochron dates used to derive the fractionation factor (Neymark et al., 2018) indicates an absolute offset $\sim 0.4 \%$ older for the LA-ICP-MS Pb-Pb isochron data. The equivalent ID-TIMS ${ }^{204} \mathrm{~Pb} /{ }^{206} \mathrm{~Pb}-{ }^{207} \mathrm{~Pb} /{ }^{206} \mathrm{~Pb}$ isochron date for this study yields $1540.9 \pm 3.6 \mathrm{Ma}$, which is broadly in concert with that derived by the LA-ICP-MS data (Neymark et al., 2018).

\subsection{Jian-1 cassiterite}

The Jian-1 cassiterite is derived from the Jiangxi W-Sn district, South China (Neymark et al., 2018). Previously,

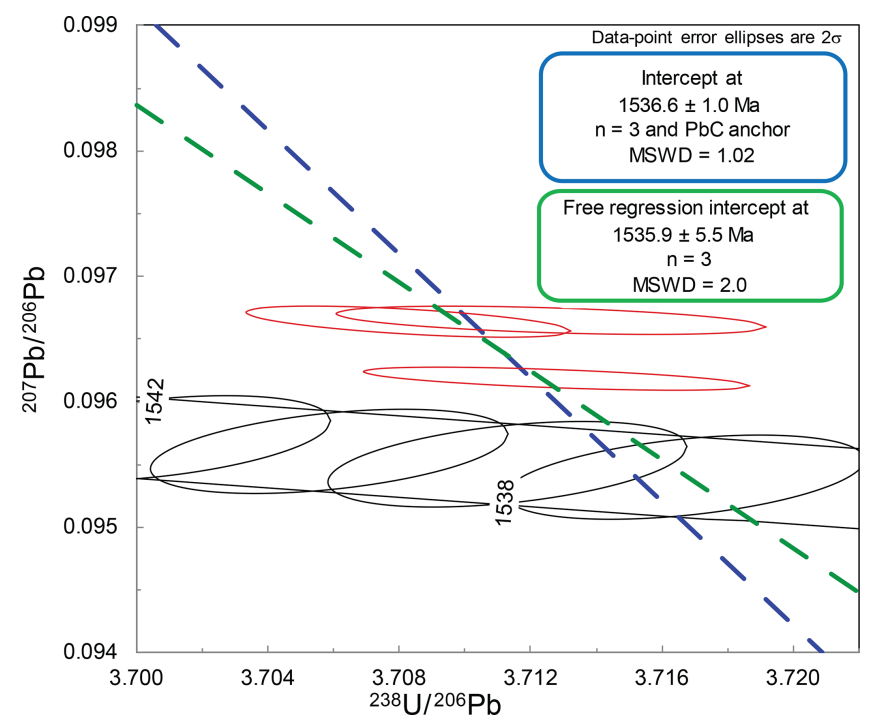

Figure 4. T-W plot of SPG-IV cassiterite showing lower intercept dates for freely regressed data (green line) and regression anchored to the $\mathrm{Pbc}{ }^{207} \mathrm{~Pb} /{ }^{206} \mathrm{~Pb}$ of galena analyses from the ore system (blue line).

an LA-ICP-MS cassiterite weighted-mean ${ }^{206} \mathrm{~Pb} /{ }^{238} \mathrm{U}$ date of $159.5 \pm 1.5 \mathrm{Ma}(n=31$; MSWD $=0.4)$ (Zhang et al., 2017) was reported for the deposit, superseded by a weighted-mean ${ }^{206} \mathrm{~Pb} /{ }^{238} \mathrm{U}$ date of $156.55 \pm 0.36 \mathrm{Ma}(n=$ 40; MSWD = 1.4) (Neymark et al., 2018). In both studies, data points overlapping concordia within uncertainty are interpreted as concordant or free of Pbc.

Four individual aliquots of the Jian-1 cassiterite were analysed by ID-TIMS. All data are discordant on the T$\mathrm{W}$ plot (Fig. 5) and are interpreted as containing a component of initial common $\mathrm{Pb}$. The total $\mathrm{Pbc}$ amounts for these analyses range from $\sim 1.5$ to $14 \mathrm{pg}$, and their ${ }^{206} \mathrm{~Pb} /{ }^{204} \mathrm{~Pb}$ ranges from $\sim 140$ to $\sim 5300$. The three data points with the greatest ${ }^{206} \mathrm{~Pb} /{ }^{204} \mathrm{~Pb}$ form a lower intercept of $155.05 \pm$ $0.20 \mathrm{Ma}(\mathrm{MSWD}=2.1)$, in agreement with the lower intercept formed by all four data points of $154.969 \pm 0.082 \mathrm{Ma}$ $(\mathrm{MSWD}=1.4)$

Comparison with LA-ICP-MS data (Fig. 5) indicates that the coarser-scale sampling of ID-TIMS analyses identified domains with lower $\mathrm{Pb}^{*} / \mathrm{Pbc}$ relative to the previously published LA-ICP-MS data (Neymark et al., 2018) and therefore provides additional spread and an isochron on the T-W plot that seemingly was not permitted by the LA-ICP-MS data. Despite this, the isochron overlaps within uncertainty with the majority of previously published LA-ICP-MS data for Jian-1 (Neymark et al., 2018), indicating that the accuracy of the measurements by microbeam was relatively robust at the $1 \%-3 \%$ precision of single data points. However, the IDTIMS lower intercept date of $154.969 \pm 0.082 \mathrm{Ma}$ is $\sim 1 \%$ younger than the LA-ICP-MS weighted-mean ${ }^{206} \mathrm{~Pb} /{ }^{238} \mathrm{U}$ date of $156.55 \pm 0.36 \mathrm{Ma}(n=40 ; \mathrm{MSWD}=1.4)$ (Neymark 
et al., 2018). This offset would likely be reduced further if a fractionation factor was renormalised to the $\sim 0.4 \%$ younger ID-TIMS intercept date of SPG-IV than was assumed by Neymark et al. (2018). However, this would still not fully account for the offset on the weighted mean at the $\pm 0.23 \%$ $2 \sigma$ precision stated for Jian-1 (Neymark et al., 2018).

\section{Evaluating the accuracy of cassiterite U-Pb dating: the geochronology of Cligga Head, SW England}

\subsection{Geology and previous geochronology of Cligga Head W-Sn deposit}

The Cligga Head W-Sn greisen deposit is located at the central-northern periphery of the post-Variscan, early Permian, SW England Cornubian Batholith, UK. Key features of the local geology (Fig. 6; Hall, 1971; Jackson et al., 1977; Moore and Jackson, 1977) are a porphyritic granite stock that intruded and locally thermally metamorphosed Devonian pelitic and psammitic meta-sediments at the contacts at about $1 \mathrm{kbar}$ (Hall, 1971). The westerly extent of the granite has been eroded by the coastline. The main granite stock is cross-cut by a complex of sheeted quartz-muscovite $(<1 \%$ topaz and fluorite) greisen-bordered veins that predominantly contain quartz, in addition to tourmaline, chlorite, fluorite, cassiterite-stannite-arsenopyrite, wolframite and minor $\mathrm{Cu}$ sulfides. The cassiterite-bearing greisen-bordered veins extend across the contact into the meta-sediments.

Rhyolite porphyry dykes intruded $\sim 150 \mathrm{~m}$ south of the stock. The absence of $\mathrm{W}-\mathrm{Sn}$ mineralisation and greisenisation of the dykes, in addition to reported xenoliths of the granite greisen within the dykes (Reid et al., 1906), indicates that they occurred after the $\mathrm{W}-\mathrm{Sn}$ mineralisation, although they contain disseminated chalcopyrite and supergene derivatives (Moore and Jackson, 1977). Previous geochronology of muscovite from the greisened zones indicated a date of $\sim 280 \mathrm{Ma}$ for the magmatic-hydrothermal system (Fig. 6). Two LA-ICP-MS U-Pb ages were presented (Moscati and Neymark, 2019) for cassiterite from Cligga Head: a TW lower intercept age of $287.9 \pm 2.6 \mathrm{Ma}(n=59$; $\mathrm{MSWD}=2.2$; initial ${ }^{207} \mathrm{~Pb} /{ }^{206} \mathrm{~Pb}$ value of $\left.0.790 \pm 0.034\right)$ or an anchored isochron with a lower intercept of $289.2 \pm$ $2.5 \mathrm{Ma}(\mathrm{MSWD}=2.4)$. The weighted-average Pbc-corrected ${ }^{206} \mathrm{~Pb} /{ }^{238} \mathrm{U}$ date is $288.4 \pm 3.0 \mathrm{Ma}(n=56, \mathrm{MSWD}=1.3)$. A second sample yielded lower intercept dates of $287.2 \pm$ $4.8 \mathrm{Ma}\left(n=40 ; \mathrm{MSWD}=2.1\right.$; initial ${ }^{207} \mathrm{~Pb} /{ }^{206} \mathrm{~Pb}$ value of $0.839 \pm 0.013)$ and a Pbc-corrected weighted-average ${ }^{206} \mathrm{~Pb} /{ }^{238} \mathrm{U}$ date of $285.2 \pm 4.2 \mathrm{Ma}(n=38, \mathrm{MSWD}=1.3)$.

\subsection{Samples and zircon CA-ID-TIMS U-Pb geochronology methods}

Samples of the granite porphyry stock and the rhyolite porphyry dyke (Fig. 6) were analysed by zircon CA-ID-TIMS
$\mathrm{U}-\mathrm{Pb}$ in order to provide constraints on the timing of cassiterite mineralisation. Zircon was analysed with the ET535 tracer, and methods followed Tapster et al. (2016) using the same decay constants and ${ }^{238} \mathrm{U} /{ }^{235} \mathrm{U}$ as the cassiterite analyses. Data are corrected for initial ${ }^{230} \mathrm{Th}$ disequilibrium using a Th / U (melt) of 1.43 derived from a mean of granitic magmatism in the Cornubian Batholith (Simons et al., 2016). All data are contained within the Supplement.

\subsection{Zircon CA-ID-TIMS U-Pb results and the "age window" for Cligga Head cassiterite}

The 10 analyses of zircon tip fragments from the host granite stock yield a range in ${ }^{206} \mathrm{~Pb} /{ }^{238} \mathrm{U}$ CA-ID-TIMS dates of $\sim 290$ to $\sim 285 \mathrm{Ma}$. The youngest four dates form a statistically acceptable weighted mean of $285.163 \pm 0.097 \mathrm{Ma}$ $(\mathrm{MSWD}=1.01 ; n=4)$, which is interpreted as the emplacement age (Fig. 6).

The eight analyses of zircon tip fragments from the porphyritic dyke, which intrudes to the SE of the stock, yield ${ }^{206} \mathrm{~Pb} /{ }^{238} \mathrm{U}$ dates of $\sim 290$ to $\sim 282 \mathrm{Ma}$. The youngest date, whilst overlapping with concordia within its relatively low single data-point uncertainty, demonstrates high discordancy $(\sim 11 \%)$ and does not form a single population weighted mean with any other dates; it is therefore attributed to residual $\mathrm{Pb}$ loss and rejected from the age interpretation. The youngest dates that form a statistically acceptable weighted-mean date yield an age of $283.21 \pm 0.032 \mathrm{Ma}$ $(\mathrm{MSWD}=0.01 ; n=3)$ taken as the timing of emplacement (Fig. 6).

The dates for magmatic events at Cligga Head provide the minimum and maximum constraints on the absolute timing of the magmatic-hydrothermal greisen system and the true "age" of cassiterite that is independent of the cassiterite isotopic dates. They define a possible window for the "true" age of cassiterite of $1.95 \pm 0.33 \mathrm{Myr}$, or about $0.7 \%$ of the $\sim 285$ Ma absolute age.

\subsection{Cligga Head cassiterite ID-TIMS U-Pb geochronology}

Cassiterite was sampled from two locations at Cligga Head (Fig. 6). From the first locality within the granite stock a single crystal $(\mathrm{C} 1)$ was used within the decomposition experiments. In the first experiment a single part of the crystal was powdered into a single "parental" aliquot and divided into eight approximately equal parts. We evaluated the effect of not leaching four of these cassiterite fractions in $29 \mathrm{M}$ HF relative to leaching, as described above and used in all of the other experiments (Fig. 7). We then evaluated intracrystal variation in $\mathrm{U}-\mathrm{Pb}$ systematics by analysing an additional three, spatially independent, parts of the same $\mathrm{C} 1$ crystal. To evaluate the inter-sample variation, fragments from four independent crystals were analysed from a second vein (C2) containing multiple cassiterite crystals that was sampled 


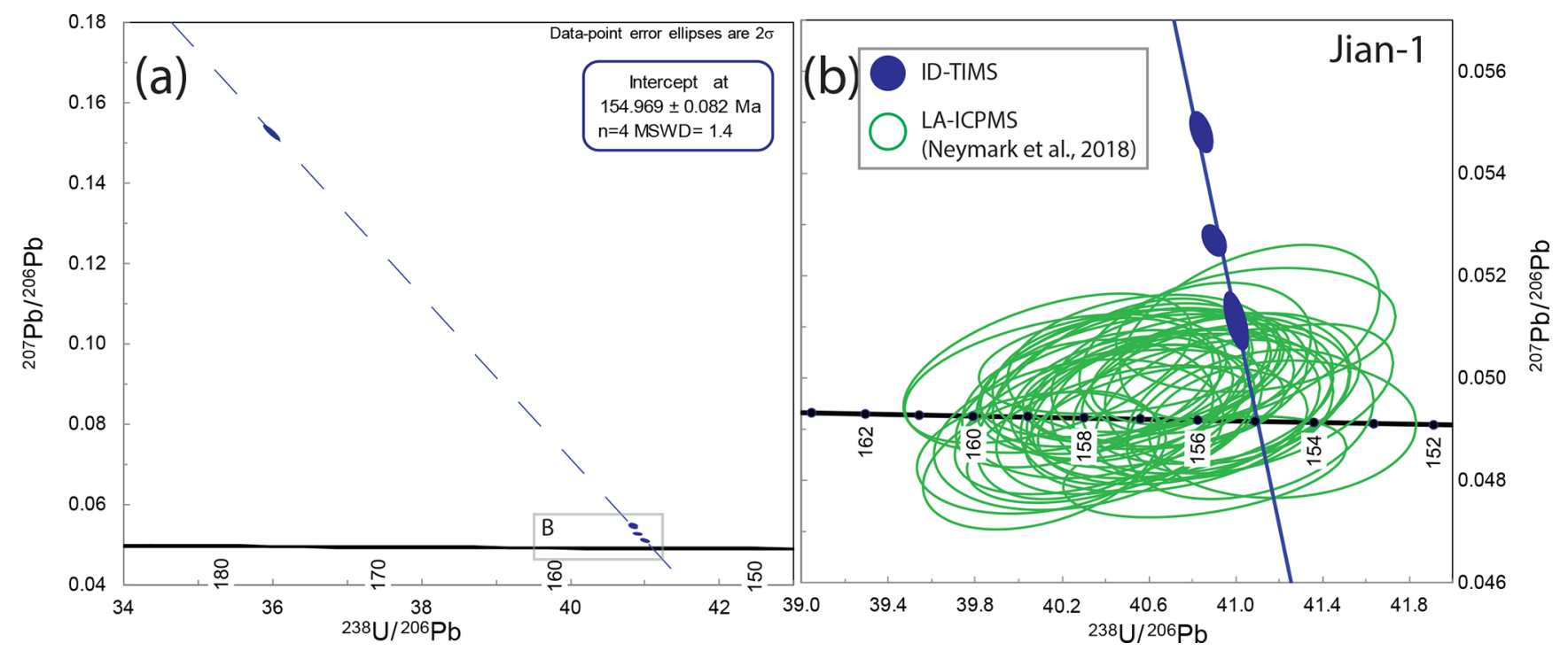

Figure 5. T-W plots of Jian-1. (a) All ID-TIMS U-Pb data and isochron; (b) ID-TIMS data excluding lowest Pb*/ Pbc and isochron lower intercept compared with LA-ICP-MS data for Jian-1 cassiterite (Neymark et al., 2018).

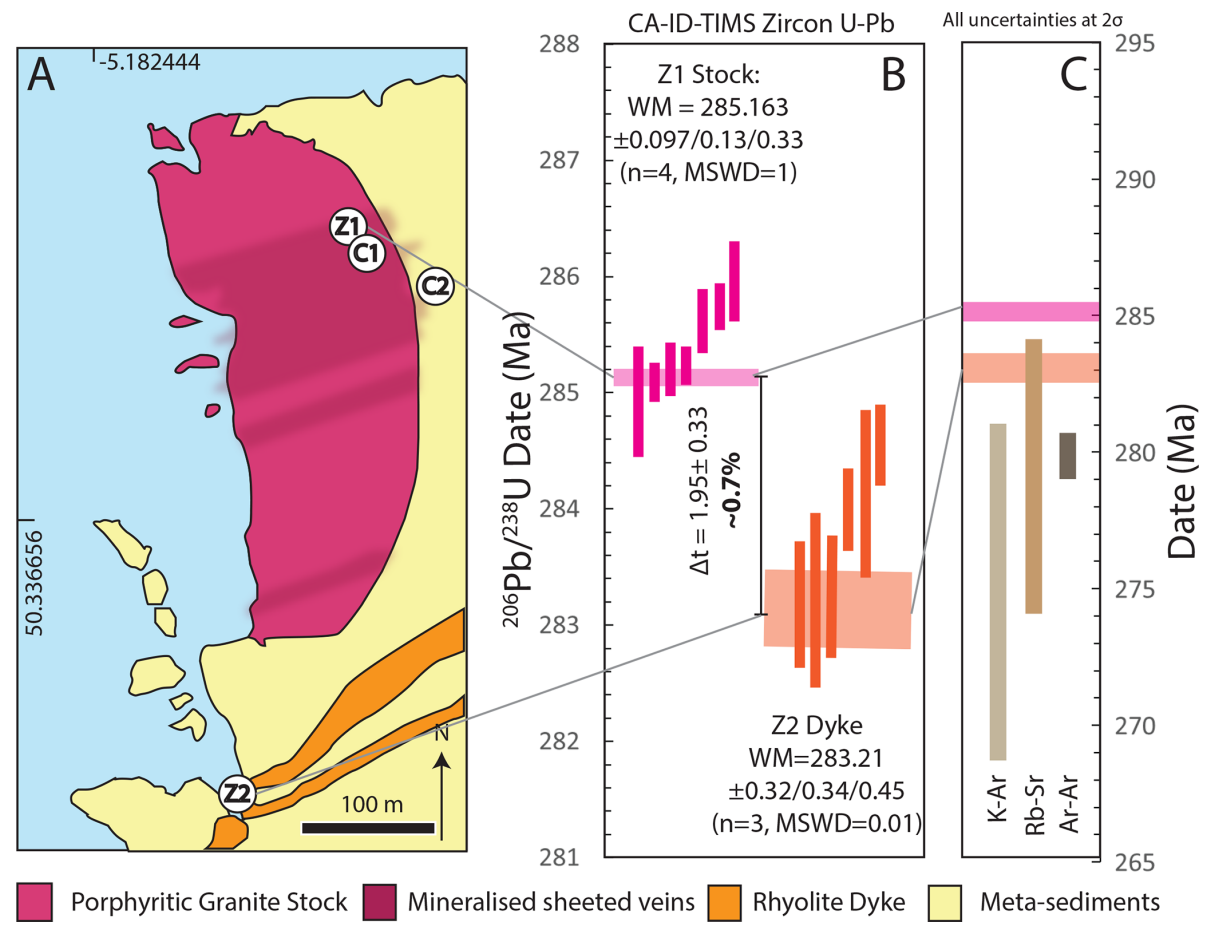

Figure 6. (a) Geological map of Cligga Head (after Moore and Jackson, 1977) with the localities of zircon samples (Z1 and Z2) and cassiterite samples (C1 and C2) marked; pale blue signifies sea level. (b) Zircon CA-ID-TIMS U-Pb dates and weighted-mean ages for Cligga Head magmatism of the porphyritic granite stock (Z1) and rhyolite porphyry dykes. Dark shaded boxes represent single analyses of zircon tips, and pale boxes represent weighted-mean dates. The intrusions define a period of $\sim 0.7 \%$ of the absolute age in which the cassiterite may have formed. Uncertainties are presented as $\pm x / y / z$, where $x$ represents analytical uncertainties only for comparison with cassiterite ID-TIMS U-Pb dates also using the ET535 tracer; $y$ represents analytical and tracer calibration uncertainties; and $z$ is the total uncertainty including the ${ }^{238} \mathrm{U}$ decay constant for comparison with ages derived from other decay systems. (c) Comparison of zircon CAID-TIMS U-Pb weighted-mean dates with previous geochronology for the greisen system (Chen et al., 1993; Halliday, 1980). 

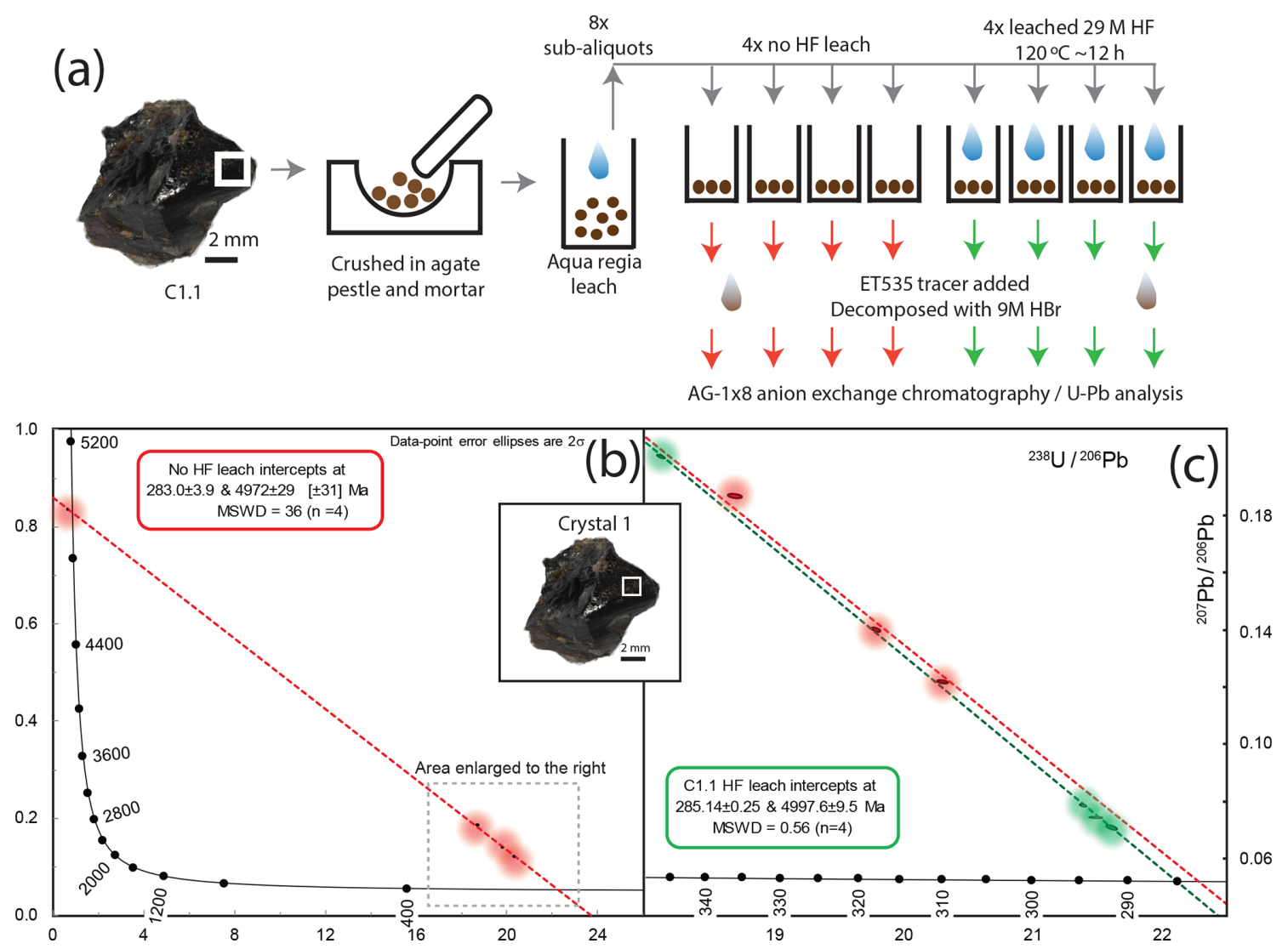

Figure 7. (a) Schematic workflow of sampling and acid pretreatment of C1.1 cassiterite. (b) T-W plot and regression of non-HF-leached sub-aliquots; individual data points are highlighted by a coloured halo due to their size at the scale of spread in the data. (c) T-W plot and regression of C1.1 HF-leached sub-aliquots (green) compared to the data and regression of non-HF-leached (red) sub-aliquots. Data are highlighted by a coloured halo due to their size at the scale of spread in the data.

from within the meta-sediments. Cassiterite ID-TIMS methods followed those described above (Sect. 5). All cassiterite $\mathrm{U}-\mathrm{Pb}$ data are contained within the Supplement.

\subsubsection{Comparison of HF-leached and non-HF-leached cassiterite from the same parental sample}

The sub-aliquots from the same parental powdered fragment of crystal (C1.1) that did not undergo HF leaching ranged from $\sim 36$ to $\sim 55 \mathrm{pg}$ of $\mathrm{Pbc}\left({ }^{206} \mathrm{~Pb} /{ }^{204} \mathrm{~Pb}=108\right.$ to 207$)$, and one aliquot yielded $7 \mathrm{ng}$ of $\mathrm{Pbc}$. Their regression line on the T-W plot forms a lower intercept of $283.0 \pm 3.9 \mathrm{Ma}$ with a statistically unacceptable MSWD of 36 . The four sub-aliquots that were HF-leached contained 6.7 to $47 \mathrm{pg}$ of $\mathrm{Pbc}\left({ }^{206} \mathrm{~Pb} /{ }^{204} \mathrm{~Pb}=97.7\right.$ to 691$)$ and yielded a lower intercept age of $285.14 \pm 0.25$ Ma with a statistically acceptable MSWD of $0.55(n=4)$ and a $y$ intercept of $0.8760 \pm 0.0058$. None of the non-HF-treated analyses form a single population (statistically acceptable MSWD) when combined with the regression line generated by the four HF treated subaliquots.

\subsubsection{Intra-grain cassiterite $\mathrm{U}-\mathrm{Pb}$ variability}

The three spatially independent aliquots from the same crystal (C1.2-C1.4) did not yield a statistically acceptable MSWD on their regression (lower intercept age $=284 \pm$ $20 \mathrm{Ma}$; MSWD $=7.2 ; n=3$ ). Only one of the three spatially distinct fragments of the same crystal fractions forms a single population with the HF-leached $\mathrm{C} 1.1$ regression line, forming a lower intercept age of $285.19 \pm 0.22 \mathrm{Ma}(n=$ 5; MSWD = 0.73). All HF-leached aliquots from the same crystal (C1) form a lower intercept age of $285.67 \pm 0.72 \mathrm{Ma}$ with a statistically unacceptable MSWD of $10.1(n=7)$. The total $\mathrm{Pbc}$ amounts for these analyses range from $\sim 3$ to $8 \mathrm{pg}$, and their ${ }^{206} \mathrm{~Pb} /{ }^{204} \mathrm{~Pb}$ ranges from $\sim 400$ to $\sim 620$.

Anchoring the lower intercept to the previously determined $\sim 285 \mathrm{Ma}$ lower intercept date of C1.1, and thus estimating the minimum possible ${ }^{207} \mathrm{~Pb} /{ }^{206} \mathrm{~Pb}$ intercept value due to the constraints offered by the granite age, yields a ${ }^{207} \mathrm{~Pb} /{ }^{206} \mathrm{~Pb}$ intercept of $0.848,0.807$ and 0.783 ( $\pm \sim 2 \%$ ), lower than the previously determined intercept of $\sim 0.876$ for the same crystal. 


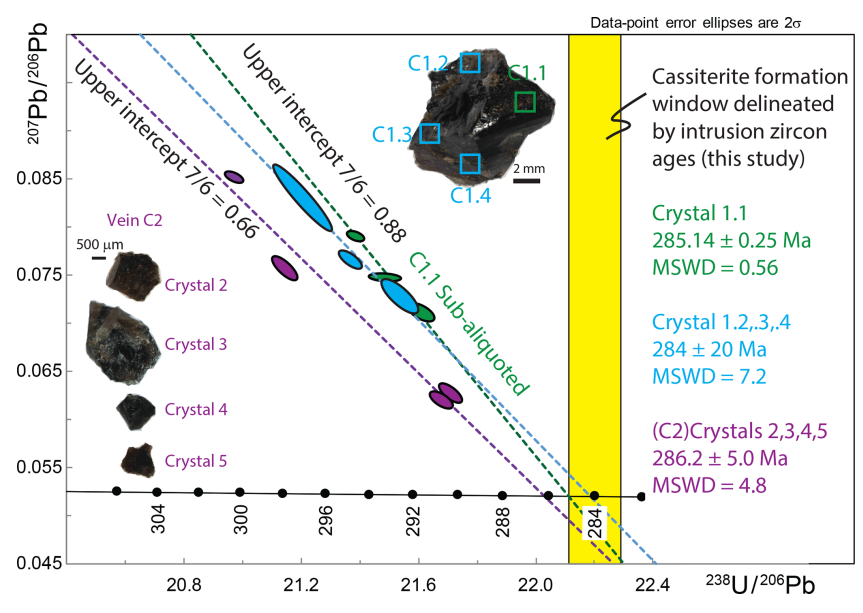

Figure 8. T-W plot and regression lines for HF-leached cassiterite from Cligga Head relative to possible age defined by zircon (Fig. 6). Regressions are for the following: C1.1 sub-aliquots $(n=4)$ as presented in Fig. 7; spatially independent samples of the same crystal $(n=3)$; and independent crystals from a different vein (C2) $(n=4)$. Note that the $y$ intercept value is for regression anchored to the maximum possible lower intercept as defined by the granite; it therefore represents a maximum $y$-intercept value. Only the sub-aliquots of $\mathrm{C} 1.1$ yield a regression without over-dispersion. See the text for further discussion.

\subsubsection{Inter-vein and -grain variation in $\mathrm{U}-\mathrm{Pb}$ systematics}

No analyses derived from individual crystals of the second hand sample (C2) form a single population when integrated with data that formed the isochron of C1.1 (Fig. 8). Neither do the four analyses form a single population between themselves, yielding a lower intercept of $286.2 \pm 5.0 \mathrm{Ma}$ with a statistically unacceptable MSWD $=48(n=4)$ and ${ }^{207} \mathrm{~Pb} /{ }^{206} \mathrm{~Pb}$ intercept of 0.72 when freely regressed and $0.66( \pm 5 \%)$ when anchored to the C1.1 lower intercept date and maximum possible age derived from the granite of $\sim 285.1 \mathrm{Ma}$ (Fig. 8). The total Pbc amounts for these analyses range from $\sim 4$ to $17 \mathrm{pg}$, and their ${ }^{206} \mathrm{~Pb} /{ }^{204} \mathrm{~Pb}$ ranges from $\sim 430$ to $\sim 1300$.

Again, to estimate the maximum initial ${ }^{207} \mathrm{~Pb} /{ }^{206} \mathrm{~Pb}$ by anchoring the lower intercept of each date the maximum possible age intercept defined by the granite yields a $y$-intercept initial ${ }^{207} \mathrm{~Pb} /{ }^{206} \mathrm{~Pb}$ for each data point of $0.695,0.643,0.595$ and $0.561( \pm 0.7 \%-2.3 \% 2 s)$, significantly lower than the value derived for $\mathrm{C} 1.1(\sim 0.876)$.

\section{Discussion}

This cassiterite $\mathrm{U}-\mathrm{Pb}$ dataset, combined with prior work (e.g. Li et al., 2016; Moscati and Neymark, 2019; Neymark et al., 2018; Zhang et al., 2017), highlights the potential for U-Pb dating of cassiterite using both microbeam and isotope dilution methods. Such datasets also reveal some complexities and issues that need to be considered when deriving meaningful ages from cassiterite dates.

\subsection{Assessing U-Pb systematics of (Cligga Head) cassiterite}

The range of ID-TIMS experiments described above permits us to evaluate the U-Pb systematics of cassiterite at high precision and within the context of independent geochronological constraints derived from zircon CA-ID-TIMS dating within a well-constrained geological model. There are three key features of the dataset.

1. The lower intercept date formed by a single population of HF-leached cassiterite sub-aliquots of the same parental material $(\mathrm{C} 1.1)$ indicates a binary mixing line between an initial $\mathrm{Pb}$ and a radiogenic $\mathrm{Pb}$ source. The lower intercept yields a precise date that is consistent with the indirect age constraints on cassiterite $\mathrm{U} / \mathrm{Pb}^{*}$. The effects of any initial isotopic disequilibrium have to be considered when deriving a sample age and uncertainty (see below).

2. The over-dispersion of non-HF-leached cassiterite compared to HF-leached C1.1 cassiterite analyses (Fig. 7) indicates non-binary mixing between initial and radiogenic $\mathrm{Pb}$. The non-HF-leached experiments contained a greater contribution of $\mathrm{Pbc}$, with the high MSWD indicating different sources and/or isotopic compositions of $\mathrm{Pbc}$ that varied in the magnitude of contribution between sub-aliquots. Both sets of experiments (Fig. 7) were treated with aqua regia prior to analysis as with previous cassiterite ID-TIMS studies (Gulson and Jones, 1992). These results therefore indicate that leaching with concentrated HF is an effective means to remove the Pbc contained within inclusions in the cassiterite that are exposed to the surface during crushing in a pestle and mortar. The results also indicate that HF leaching is effective in removing Pbc-bearing contaminants introduced by crushing a in pestle and mortar, as proposed as a potential issue by Neymark et al. (2018). The acid-resistant nature of cassiterite and ability of HF to dissolve silicate minerals without partially dissolving the cassiterite, potentially leading to the incongruous removal of $\mathrm{Pb}$ or $\mathrm{U}$, make this an important step to remove non-lattice-bound $\mathrm{Pbc}$ prior to decomposition by $\mathrm{HBr}$ and improve the accuracy of resulting ID-TIMS U-Pb dates.

3. The differences between spatially independent samples from within and between crystals, and between cassiterites from different veins (Fig. 8), indicate localised controls on the $\mathrm{U}-\mathrm{Pb}$ systematics of cassiterite. Only one spatially independent fragment from the same crystal of cassiterite forms a single population with the isochron of HF-leached C1.1 described above. A dataset 
based upon aliquots of the same crystals $(\mathrm{C} 1.2, \mathrm{C} 1.3$, $\mathrm{C} 1.4$ ) yields a similar age as the $\mathrm{C} 1.1$ isochron but is over-dispersed and the lower intercept is less precise. A similar cassiterite U-Pb ID-TIMS dataset from a different vein $(\mathrm{C} 2)$ is also over-dispersed and plots distinctly to the left of the $\mathrm{C} 1$ mixing array between the constrained crystallisation age and initial $\mathrm{Pbc}{ }^{207} \mathrm{~Pb} /{ }^{206} \mathrm{~Pb}$ compositions.

Open-system behaviour with respect to $\mathrm{Pb}(\mathrm{Pb}$ loss) would shift data points to the right (higher $\mathrm{U} / \mathrm{Pb}$ ) of the $\mathrm{C} 1.1$ (or similar) isochron. Estimated uranium concentrations (see the cassiterite ID-TIMS U-Pb data table in the Supplement) are similar between cassiterites from the two veins and as such there is no apparent reason why uranium mobility would be manifest to a greater extent between different veins. We consider the most likely explanation to be that the overdispersion results from variation in the initial $\mathrm{Pbc}$ of the cassiterite to more "radiogenic" initial ${ }^{207} \mathrm{~Pb} /{ }^{206} \mathrm{~Pb}$ values than $\sim 0.88$ as defined by the $\mathrm{C} 1.1$ isochron, potentially as low as $\sim 0.56$. The majority of documented ${ }^{207} \mathrm{~Pb} /{ }^{206} \mathrm{~Pb}$ values from feldspars in granites and fluid inclusions in the Cornubian Batholith are 0.8-0.9 (Hampton and Taylor, 1983; Wayne et al., 1996), with only one magmatic feldspar analysis yielding a ${ }^{207} \mathrm{~Pb} /{ }^{206} \mathrm{~Pb}$ of $\sim 0.55$ (Hampton and Taylor, 1983). It is unlikely that these low values reflect the primary input signature from the magmatic volatiles. Initial $\mathrm{Pb}$ values with ${ }^{207} \mathrm{~Pb} /{ }^{206} \mathrm{~Pb}$ this low are uncommon but are present in a global array of vein carbonates (Roberts et al., 2020). When the nature of cassiterite-bearing greisen systems, such as Cligga Head, is taken into account, the ability to generate atypical $\mathrm{Pbc}$ isotopic compositions is less surprising. Greisenisation at the margins of the cassiterite-bearing veins represents extensive, destructive, fluid-rock interaction and elemental exchange during alteration of host rocks by high temperatures of $\sim 450-300^{\circ} \mathrm{C}$ and highly acidic, fluorine-rich (HF) fluids (Burt, 1981; Codeço et al., 2017; Lecumberri-Sanchez et al., 2017). As at Cligga Head, W-Sn greisen-bordered vein magmatic-hydrothermal deposits are commonly hosted by, or are proximal to, thick continentally derived sedimentary packages (Lecumberri-Sanchez et al., 2017) that likely represent the source of Sn enrichment prior to magma genesis (Romer and Kroner, 2016). These sediments will contain older $\mathrm{U}$ - and $\mathrm{Pb}^{*}$-rich continental mineral detritus (e.g. zircon, monazite) that can be extensively leached by the hot, F-rich, acidic ore-forming fluid, generating significant spatial and temporal variations in the $\mathrm{Pbc}$ isotopic composition incorporated into the cassiterite lattice over the lifetime of single crystal precipitation and the magmatic hydrothermal system as a whole. It is perhaps significant that the cassiterite that appears to contain the lowest initial $\mathrm{Pbc}$ component originates from a vein bordered by greisened meta-sediment rather than being hosted within the granitic stock.

\subsection{Cassiterite $\mathrm{U}-\mathrm{Pb}$ ages and effects of initial $\mathrm{U}-\mathrm{Th}$ disequilibrium}

The high-precision U-Pb lower intercept cassiterite date (C1.1; Figs. 7 and 8) comes with the caveat that it is not corrected for potential initial isotopic disequilibrium effects within the ${ }^{238} \mathrm{U}$ decay chain. In zircon geochronology a deficit in ${ }^{206} \mathrm{~Pb}$ due to ${ }^{230} \mathrm{Th}$ disequilibrium (Schärer, 1984) can be reasonably corrected using a reasonable assumption of the mineral-melt partition coefficient or an estimate of melt Th / U, as well as an estimate of mineral Th / U, typically based on assumed ${ }^{208} \mathrm{~Pb} /{ }^{232} \mathrm{Th}-{ }^{206} \mathrm{~Pb} /{ }^{238} \mathrm{U}$ concordance for zircon ID-TIMS data. Cassiterite typically has extremely low ${ }^{232} \mathrm{Th}$ relative to $\mathrm{U}$ ( $\mathrm{Th} / \mathrm{U}=<10^{-4}$; Neymark et al., 2018). This geochemical feature may be derived from the preferential partitioning of $U$ into ore fluids and/or the preferential partitioning of $U$ upon the precipitation of cassiterite, leading to a deviation from secular equilibrium. Both processes will require a significant correction for a deficiency in ${ }^{206} \mathrm{~Pb}$ due to low ${ }^{230} \mathrm{Th} /{ }^{238} \mathrm{U}$ activity in the initial cassiterite. Alternatively, this geochemical feature could simply be explained by processes that do not preclude secular equilibrium with regards to ${ }^{230} \mathrm{Th}$ upon cassiterite crystallisation. These include low ${ }^{232} \mathrm{Th} /{ }^{238} \mathrm{U}$ magmatic ore fluid sources or the contribution of localised U-rich components to fluids that are in secular equilibrium with regards to ${ }^{230} \mathrm{Th}$ and ${ }^{238} \mathrm{U}$ during alteration around veins. In these cases the ${ }^{232} \mathrm{Th}-$ ${ }^{208} \mathrm{~Pb}$ system would not provide a realistic proxy for initial ${ }^{230} \mathrm{Th}$ disequilibrium in cassiterite.

It must also be considered that the hydrothermal fluids, and therefore the initial cassiterite, may not have been in secular equilibrium for ${ }^{238} U-{ }^{234} U$. A relative excess of ${ }^{234} U$ or a ${ }^{234} \mathrm{U} /{ }^{238} \mathrm{U}$ activity ratio $>1$ at the time of cassiterite precipitation will result in an excess of ${ }^{206} \mathrm{~Pb} /{ }^{238} \mathrm{U}$, an older measured date relative to the true age. These effects therefore counteract effects of ${ }^{206} \mathrm{~Pb}$ deficiency due to ${ }^{230} \mathrm{Th}$ disequilibrium. Mixing with meteoric fluids appears to be an important process in cassiterite formation (Fekete et al., 2016), and as highlighted by the compilation of Roberts et al. (2020) the ${ }^{234} \mathrm{U} /{ }^{238} \mathrm{U}$ activity of crustal fluids can be in excess of 1 (shallow groundwater median value of 2.25 ; hydrothermal fluid median of 1.41).

Estimates of the effects of initial disequilibrium (Fig. 9) indicate that corrections for the exclusion (or absence) of initial ${ }^{230} \mathrm{Th}$, potentially inferred by the characteristic low ${ }^{232} \mathrm{Th} / \mathrm{U}$ in cassiterite, produces a maximum possible date $(\sim 285.23 \mathrm{Ma})$ that is still within uncertainty of the maximum age permitted by the granite host. Effects of excess initial ${ }^{234} \mathrm{U}$ indicate that an activity ratio of 1.5 produces dates $\sim 200 \mathrm{kyr}$ younger $(284.92 \mathrm{Ma})$ than that of secular equilibrium, yet it also lies within the analytical uncertainties of the host granite. In the more extreme scenario of a ${ }^{234} \mathrm{U} /{ }^{238} \mathrm{U}$ activity ratio of 2.5 , this is reduced to $284.55 \mathrm{Ma}$ and would be significantly younger. 


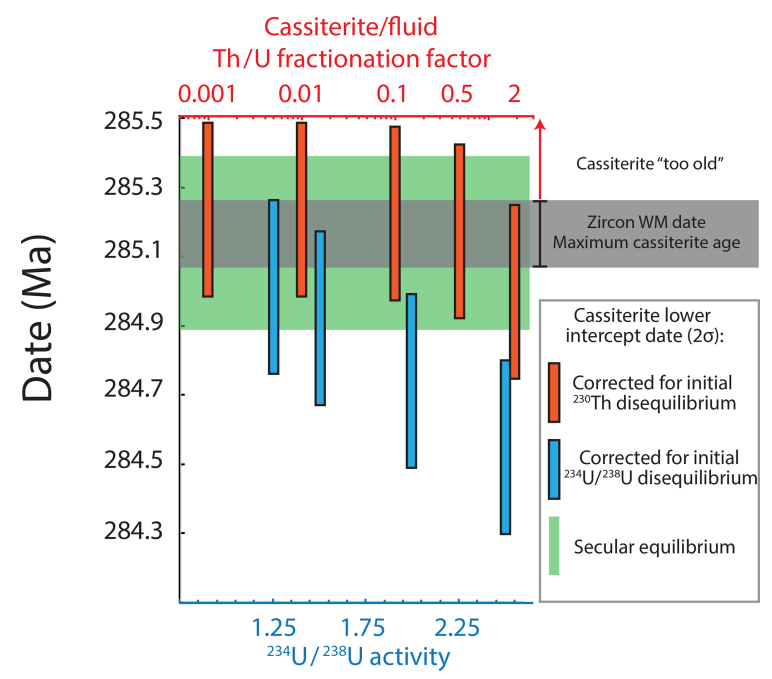

Figure 9. Effects of corrections for initial intermediate daughter disequilibrium on the lower intercept date of $\mathrm{C} 1.1$ regression over geologically feasible parameters. Note that corrections are treated independently and that combinations of initial disequilibrium effects could be present. The maximum possible age of cassiterite is defined by the zircon age and the uncertainty of the porphyritic granite stock that hosts the cassiterite-bearing veins. See the text for discussion.

Not accounting for the uncertainty that arises from the potential effects of disequilibrium, the lower intercept of the four-point isochron $\mathrm{C} 1.1$ yields a precision of $\pm 250 \mathrm{kyr}$ or $0.088 \%$ ( $2 \sigma$, analytical uncertainties only) and agreement with the possible window for hydrothermal activity defined by the CA-ID-TIMS zircon dates of the intrusions $(\sim 0.7 \%)$. Moreover, it also demonstrates a clear temporal association with the granitic stock that hosts the Cligga Head deposit (the cassiterite date is $0.021 \pm 0.268 \mathrm{Myr}$ younger than the zircon date for the granitic stock) (Figs. 9, 10). High-precision constraints on the durations of relatively simple ore-forming magmatic-hydrothermal systems spatially associated with single intrusions indicate timeframes of tens to hundreds of thousands of years ( $\mathrm{Li}$ et al., 2017; Tapster et al., 2016). It is therefore feasible that the emplacement of the host granite stock, cooling to the $400-350^{\circ} \mathrm{C}$ temperature interval of cassiterite precipitation (Smith et al., 1996), and the transfer of ore-forming volatiles from depth all occurred within the timeframes defined by the $<0.1 \%$ uncertainty of the zircon and cassiterite data presented here. However, considering the potential uncertainty due to initial U-Th disequilibrium effects over geologically reasonable assumptions, the cassiterite uncertainty could be expanded by ca. $-200 \mathrm{kyr}$ and would be asymmetric (Fig. 9). At present the poor understanding of isotopic disequilibrium effects due to elemental partitioning into ore fluids and cassiterite represents a limitation for the accurate interpretation of absolute ages of cassiterite beyond the $<\sim 500 \mathrm{kyr}$ timescale.

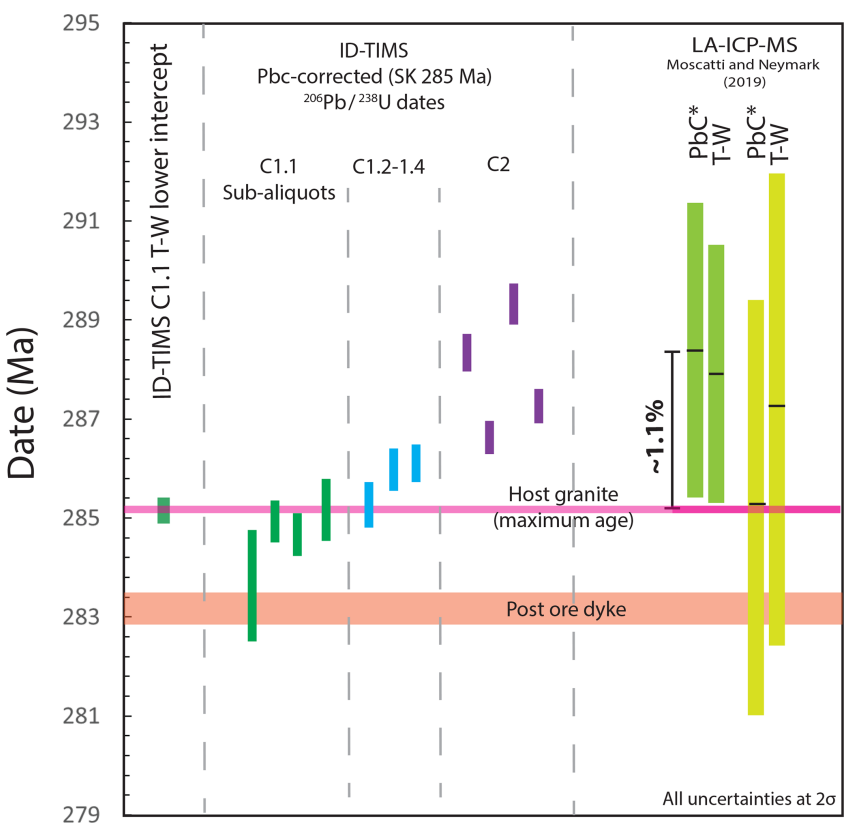

Figure 10. The effects of using a correction for $\mathrm{Pbc}$ on the ${ }^{206} \mathrm{~Pb} /{ }^{238} \mathrm{U}$ dates of single analyses of cassiterite; in this case a model Pbc value at $285 \mathrm{Ma}$ (Stacey and Kramers, 1975) was used. Data are shown relative to the freely regressed ID-TIMS lower intercept of C1.1 that shows excellent agreement with the host granite age. Pbc-corrected dates range from being in good agreement with the age constraints to being offset by $\sim 4$ Myr relative to the maximum possible age of cassiterite defined by zircon dates for the granite. The samples analysed in a previous LA-ICP-MS study from Cligga Head (Moscati and Neymark, 2019) illustrate similar magnitudes, and the direction of offset can be observed in both the TW regressions. Despite the agreement of the Pbc-corrected $\left(\mathrm{Pbc}^{*}\right)$ weighted-mean ${ }^{206} \mathrm{~Pb} /{ }^{238} \mathrm{U}$ date $290 \mathrm{Ma}$ (Stacey and Kramers, 1975) of one sample, this approach to data interpretation is invalid; see the text for discussion.

\subsection{Implications and strategies for LA-ICP-MS U-Pb cassiterite geochronology}

In this study we have generated ID-TIMS U-Pb data on cassiterite that has undergone full decomposition in a single stage. These include samples that have previously been used for LA-ICP-MS studies using an approach to $\mathrm{U} / \mathrm{Pb}$ normalisation using an ad hoc cassiterite reference material with an inferred $\mathrm{U} / \mathrm{Pb}$ age. The comparison of the ID-TIMS and LA-ICP-MS U-Pb data provides a direct means to assess the accuracy of the microbeam dates (Moscati and Neymark, 2019; Neymark et al., 2018), which show agreement at the ca. $1 \%$ level and are therefore comparable to the quoted levels of accuracy and similar to the accuracy for $\mathrm{U}-\mathrm{Pb}$ (zircon) studies (Horstwood et al., 2016). Additional characterisation over a wider range of cassiterite materials by the ID-TIMS methods described here will establish a focal point for the refinement of cassiterite measurement uncertainties by LAICP-MS. 
The ID-TIMS U-Pb data from the Cligga Head cassiterite strongly suggest that the initial $\mathrm{Pb}$ isotopic composition varies and that a simple binary mixture between a radiogenic and initial $\mathrm{Pb}$ may not be expected within and between crystals. A high proportion of LA-ICP-MS U-Pb cassiterite datasets record over-dispersion (e.g. $\sim 2 / 3$ of samples, typically analysed from single crystals; reported by Neymark et al., 2018), suggesting that these are also not strict binary mixtures. We postulate that some of the over-dispersion can be attributed to variable initial $\mathrm{Pb}$ isotopic compositions within cassiterite that are inherited from the hydrothermal systems. This complexity in the U-Pb systematics represents a potential limitation on the accuracy of the resulting age interpretation of cassiterite. This limitation is interdependent with the single data-point precision of the $\mathrm{U}-\mathrm{Pb}$ analyses and the ability to resolve different populations of the $\mathrm{Pbc}$ mixing endmember that will bias the regression of a dataset away from the accurate lower intercept.

We explore how the $\mathrm{U}-\mathrm{Pb}$ data can be leveraged with variable Pbc by correcting the Cligga Head dataset using a widely employed strategy for minerals that accommodates $\mathrm{Pb}$ into their lattice upon formation, which involves correcting the component of initial $\mathrm{Pbc}$ using a model $\mathrm{Pbc}$ value at $\sim 285 \mathrm{Ma}$ (Stacey and Kramers, 1975). Figure 10 demonstrates that the resulting Pbc-corrected ${ }^{206} \mathrm{~Pb} /{ }^{238} \mathrm{U}$ dates range from being in good agreement with the host granite age to being "too old" by ca. $4 \mathrm{Myr}(\sim 1.5 \%)$. Without the maximum constraint from the age of the granite, these "model" $\mathrm{U}-\mathrm{Pb}$ cassiterite dates alone could be misinterpreted as a protracted episode of mineralisation. Comparable shifts, both in magnitude and direction, can be observed (Fig. 10) within one of the two samples from the same deposit that were analysed by LA-ICP-MS U-Pb (Moscati and Neymark, 2019).

Figure 11 illustrates how the ability to resolve this effect and the interplay with lower precision on single data points can impact the accuracy of the regression and age interpretation. The isochron we construct is based upon all Cligga Head cassiterite ID-TIMS U-Pb analyses but with uncertainties expanded to $\pm 1 \%(2 \sigma)$ (Fig. 11). It shows no dispersion (MSWD $=1.2, n=12$ ); however, the resulting age is biased too old (lower intercept at $286.80 \pm 0.95 \mathrm{Ma}$ ) for the known maximum possible age that is defined by the granite.

The approach of taking weighted means of common $\mathrm{Pb}$ corrected ${ }^{206} \mathrm{~Pb} /{ }^{238} \mathrm{U}$ data is strongly advised against, as it diminishes the evaluation of dispersion within the data and ignores the uncertainty of ${ }^{207} \mathrm{~Pb} /{ }^{206} \mathrm{~Pb}$ measurements (see Horstwood et al., 2015, for community discussion of this issue in LA-ICP-MS U-Pb). However, to demonstrate that this approach does not resolve the issues of variable initial $\mathrm{Pbc}$ composition, the weighted-mean date of Pbc-corrected ${ }^{206} \mathrm{~Pb} /{ }^{238} \mathrm{U}$ dates for the same dataset with uncertainties expanded to $1 \%$ is $286.23 \pm 0.83 \mathrm{Ma}$ (MSWD $=1.3 ; n=12$; therefore, despite its seemingly precise date, it also lies outside the uncertainty of the maximum possible age defined by the granite.

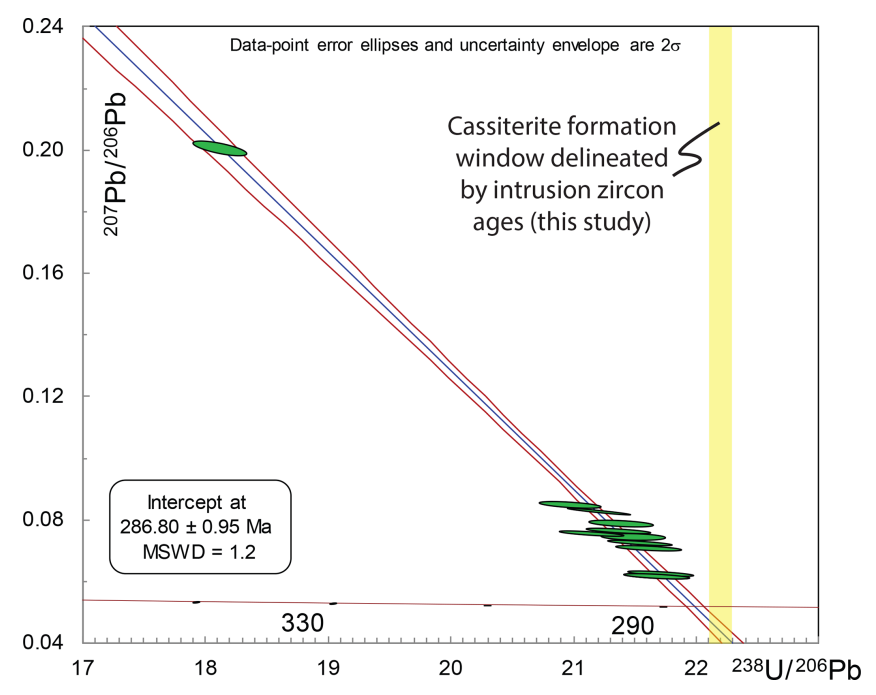

Figure 11. Illustration of how variable Pbc compositions in cassiterite form a "single population", yet with an inaccurate T-W lower intercept within lower single data-point precision datasets. The data are all HF-leached ID-TIMS U-Pb data from Cligga Head with artificially expanded single data-point uncertainties of $1 \%(2 s)$ for both ${ }^{238} \mathrm{U} /{ }^{206} \mathrm{~Pb}$ and ${ }^{207} \mathrm{~Pb} /{ }^{206} \mathrm{~Pb}$. This level of uncertainty is therefore a reasonable illustration of the upper range of analytical precision that may be achieved through microbeam techniques in relatively low-U-concentration materials such as cassiterite. Note that the data with artificial uncertainties do not show excess dispersion (statistically acceptable MSWD) but produce a relatively precise lower intercept $(0.33 \%)$ outside the uncertainty and older than the maximum permitted age of cassiterite delineated by the granite (Fig. 6). This does not factor in any additional systematic or analytical inaccuracy from lower-precision methods.

Any bias resulting from $\mathrm{Pbc}$ variation would be in addition to greater scatter on individual data points resulting from lower-precision measurements. This reinforces the limitations on the accuracy of the interpreted ages when derived from high- $n$ but lower-precision datasets due to heterogeneity being masked by the single data-point uncertainty. In addition to the limits of systematic uncertainties defined by validation RMs, this limitation should be taken into account within future microbeam work with cassiterite, alongside any mineral phase that contains initial Pbc.

We note that the reference values of any cassiterite material used as an RM should not be corrected for $\mathrm{Pbc}$ or any initial isotopic disequilibrium effects; rather, they should reflect the isotopic values of the material ablated (Horstwood et al., 2016), as with the data presented in Figs. 4, 5, 7 and 8. HF leaching of cassiterite targets inclusions and is unlikely to affect lattice-bound $\mathrm{Pb}$ and modify the isotope ratios as chemical abrasion does for zircon RMs. 


\section{Conclusions}

The absolute dating of cassiterite using the U-Pb decay system offers the potential to link the hydrothermal processes responsible for Sn mineralisation to the regional- and localscale (deposit) magmatic-hydrothermal systems that may or may not be related to their genesis. Recent studies (e.g. Liu et al., 2007; Moscati and Neymark, 2019; Neymark et al., 2018; Yuan et al., 2011, 2008; Zhang et al., 2017; and others) have demonstrated the potential of cassiterite for $\mathrm{U}-\mathrm{Pb}$ geochronology using microbeam methods (LA-ICP-MS) applied to the mineral from a wide range of deposits. The lack of materials that have characterised $\mathrm{U}-\mathrm{Pb}$ compositions via total dissolution isotope dilution methods, and the difficulties in obtaining these, has led to the development of calibrations using inferred ages for ad hoc reference materials and impedes the verification of $\mathrm{U}-\mathrm{Pb}$ datasets generated. We have demonstrated that useful amounts of cassiterite can be fully decomposed under closed-system conditions using readily obtainable and low-Pbc blank $\mathrm{HBr}$ acid over timescales and with an apparatus similar to those used in zircon ID-TIMS work. Increasing the surface area to volume ratio (e.g. using a pestle and mortar) is in fact an advantage when utilised with an HF-leaching step, as it not only expedites cassiterite decomposition, but will also expose Pbc-bearing inclusions that can be leached and rinsed away, along with any material abraded during crushing in a pestle and mortar. The notorious acid resistance of cassiterite works to our advantage as HF leaching leaves the lattice-bound U-Pb systematics intact. The methodology presented here indicates that $\mathrm{Pb}$ can be isolated using a simple modification of the AG- $1 \mathrm{x} 8$ resin $\mathrm{HCl}$-based anion exchange chromatography typically used for zircon, with no detectable penalties for ionisation by TIMS, and a further AG-1 $1 \times 8 \mathrm{HCl}-$ and $\mathrm{HNO}_{3}$-based scheme is effective for the $\mathrm{U}$ elution.

The U-Pb ID-TIMS data presented for a range of materials between $\sim 150$ and $\sim 1600 \mathrm{Ma}$ demonstrate that cassiterite ID-TIMS U-Pb geochronology can potentially generate $\mathrm{U}-\mathrm{Pb}$ lower intercept dates at $\pm<0.1 \%$ precision from a relatively low number of analyses. Using the classic example of the W-Sn greisen deposit at Cligga Head, UK, we demonstrate that the implementation of "internal isochrones" from sub-aliquots of powdered fragments can derive a U-Pb IDTIMS cassiterite age interpretation consistent with an independent high-precision zircon CA-ID-TIMS U-Pb constraint on the age of cassiterite. These direct constraints show that the hydrothermal system was relatively short-lived, illustrating the potential of this method to define causative magmatic events. However, unknowns regarding the initial isotopic disequilibrium of cassiterite probably limit the true uncertainty on the age to $\sim 400 \mathrm{kyr}$.

Comparison of ID-TIMS and previously reported LA-ICPMS U-Pb datasets for the three samples indicates that the latter are accurate at the $\sim 1 \%(2 \sigma)$ level, especially when taking into account the ID-TIMS date that was $\sim 0.4 \%$ younger than the inferred age for the SPG-IV cassiterite used to normalise matrix effects in the Neymark et al. (2018) study. This direct $\mathrm{U} / \mathrm{Pb}$ determination can be used to refine LA-ICP-MS data that are normalised to this ad hoc reference material, further improving the underpinning of cassiterite $\mathrm{U}-\mathrm{Pb}$ via LA-ICP-MS. Further total-digestion ID-TIMS U-Pb analyses of cassiterite will further improve the method, hopefully providing additional reference materials for calibration and verification.

The high-precision data presented here indicate that intraand inter-grain variations occur in the isotopic composition of $\mathrm{Pbc}$ present within the cassiterite. The nature of greisen Sn hydrothermal systems and their association with continentally derived sedimentary packages may be conducive to localised and variably radiogenic $\mathrm{Pbc}$ compositions. The potential for these variations in Pbc compositions places limitations on the interpretive power of datasets as a function of single data-point precision. A cautious approach to the age interpretation of lower-precision microbeam datasets, beyond the issues of analytical precision, is advised.

Data availability. Data to reproduce all plots presented here are provided within the Supplement Excel workbook.

Supplement. The supplement related to this article is available online at: https://doi.org/10.5194/gchron-2-425-2020-supplement.

Author contributions. ST and JB designed the experiments that were carried out by JB with contributions from ST. ST interpreted the data and prepared the paper with contributions from JB.

Competing interests. The authors declare that they have no conflict of interest.

Acknowledgements. The authors are extremely thankful for the provision of cassiterite materials by Richard Taylor, Richard Shaw and Leonid Neymark (USGS). We thank Jeremy Rushton and Gren Turner at the BGS SEM facility. The authors thank Dan Condon and Matt Horstwood for discussion and comments on this paper. We gratefully acknowledge the careful and constructive reviews that contributed to the accuracy of the paper by Corey Wall and Gavin Piccione.

Review statement. This paper was edited by Brenhin Keller and reviewed by Corey Wall and Gavin Piccione.

\section{References}

Amelin, Y. V, Larin, A. M., and Tucker, R. D.: Chronology of multiphase emplacement of the Salmi rapakivi granite-anorthosite 
complex, Baltic Shield: implications for magmatic evolution, Contrib. Mineral. Petr., 127, 353-368, 1997.

Bowring, J. F., McLean, N. M., and Bowring, S. A.: Engineering cyber infrastructure for $\mathrm{U}-\mathrm{Pb}$ geochronology: Tripoli and U-Pb_Redux, Geochem. Geophy. Geosy., 12, Q0AA19, https://doi.org/10.1029/2010GC003479, 2011.

Burt, D. M.: Acidity-salinity diagrams; application to greisen and porphyry deposits, Econ. Geol., 76, 832-843, 1981.

Caley, E. R.: The action of hydriodic acid on stannic oxide, J. Am. Chem. Soc., 54, 3240-3243, 1932.

Carr, P. A., Norman, M. D., and Bennett, V. C.: Assessment of crystallographic orientation effects on secondary ion mass spectrometry (SIMS) analysis of cassiterite, Chem. Geol., 467, 122-133, 2017.

Chen, Y., Clark, A. H., Farrar, E., Wasteneys, H., Hodgson, M. J., and Bromley, A. V: Diachronous and independent histories of plutonism and mineralization in the Cornubian Batholith, southwest England, J. Geol. Soc. London, 150, 1183-1191, 1993.

Cheng, H., Edwards, R. L., Hoff, J., Gallup, C. D., Richards, D. A., and Asmerom, Y.: The half-lives of uranium-234 and thorium230, Chem. Geol., 169, 17-33, 2000.

Clayton, R., Andersson, P., Gale, N. H., Gillis, C., and Whitehouse, M. J.: Precise determination of the isotopic composition of Sn using MC-ICP-MS, J. Anal. At. Spectrom., 17, 1248-1256, 2002.

Codeço, M. S., Weis, P., Trumbull, R. B., Pinto, F., LecumberriSanchez, P., and Wilke, F. D. H.: Chemical and boron isotopic composition of hydrothermal tourmaline from the Panasqueira W-Sn-Cu deposit, Portugal, Chem. Geol., 468, 1-16, 2017.

Condon, D. J., Schoene, B., McLean, N. M., Bowring, S. A., and Parrish, R. R.: Metrology and traceability of U-Pb isotope dilution geochronology (EARTHTIME Tracer Calibration Part I), Geochim. Cosmochim. Acta, 164, 464-480, 2015.

Doležal, J., Lenz, J., and Šulcek, Z.: Decomposition by pressure in inorganic analysis, Anal. Chim. Acta, 47, 517-527, 1969.

Farmer, C. B., Searl, A., and Halls, C.: Cathodoluminescence and growth of cassiterite in the composite lodes at South Crofty Mine, Cornwall, England, Mineral. Mag., 55, 447-458, 1991.

Fekete, S., Weis, P., Driesner, T., Bouvier, A.-S., Baumgartner, L., and Heinrich, C. A.: Contrasting hydrological processes of meteoric water incursion during magmatic-hydrothermal ore deposition: An oxygen isotope study by ion microprobe, Earth Planet. Sci. Lett., 451, 263-271, 2016.

Gerstenberger, H. and Haase, G.: A highly effective emitter substance for mass spectrometric $\mathrm{Pb}$ isotope ratio determinations, Chem. Geol., 136, 309-312, 1997.

Gulson, B. L. and Jones, M. T.: Cassiterite: Potential for direct dating of mineral deposits and a precise age for the Bushveld Complex granites, Geology, 20, 355-358, 1992.

Hall, A.: Greisenisation in the granite of Cligga Head, Cornwall, P. Geologist. Assoc., 82, 209-IN1, 1971.

Hall, A.: The determination of total tin content of some geological materials by atomic absorption spectrophotometry, Chem. Geol., 30, 135-142, 1980.

Halliday, A. N.: The timing of early and main stage ore mineralization in Southwest Cornwall, Econ. Geol., 75, 752-759, https://doi.org/10.2113/gsecongeo.75.5.752, 1980.

Hampton, C. M. and Taylor, P. N.: The age and nature of the basement of southern Britain: evidence from $\mathrm{Sr}$ and $\mathrm{Pb}$ isotopes in granites, J. Geol. Soc. London., 140, 499-509, 1983.
Haustein, M., Gillis, C., and Pernicka, E.: Tin isotopy-a new method for solving old questions, Archaeometry, 52, 816-832, 2010.

Hiess, J., Condon, D. J., McLean, N., and Noble, S. R.: 238U/235U systematics in terrestrial uranium-bearing minerals, Science, 335, 1610-1614, 2012.

Horstwood, M., Jackson, S., Gehrels, G., Sylvester, P., and Pearson, N.: LA-ICP-MS U-Th-Pb Network Workshop, in: Prague Goldschmidt, 15-16 August 2015, Plasmage.org, Prague, available at: http://plasmage.org/docs/Prague2015WorkshopReport. pdf (last access: 19 December 2019), 2015.

Horstwood, M. S. A., Košler, J., Gehrels, G., Jackson, S. E., McLean, N. M., Paton, C., Pearson, N. J., Sircombe, K., Sylvester, P., Vermeesch, P., Bowring, J. F., Condon, D. J., and Schoene, B.: Community-Derived Standards for LA-ICP-MS U(Th-)Pb Geochronology - Uncertainty Propagation, Age Interpretation and Data Reporting, Geostand. Geoanal. Res., 40, 311 332, https://doi.org/10.1111/j.1751-908X.2016.00379.x, 2016.

Jackson, N. J., Moore, J. M., and Rankin, A. H.: Fluid inclusions and mineralization at Cligga Head, Cornwall, England, J. Geol. Soc. London, 134, 343-349, 1977.

Jaffey, A. H., Flynn, K. F., Glendenin, L. E., Bentley, W. C., and Essling, A. M.: Precision measurement of half-lives and specific activities of ${ }^{235} \mathrm{U}$ and ${ }^{238} \mathrm{U}$, Phys. Rev. C, 4, 1889, https://doi.org/10.1103/PhysRevC.4.1889, 1971.

Kesler, S. E. and Wilkinson, B. H.: Tectonic-diffusion estimates of global mineral resources: extending the method: granitic tin deposits, J. Geol. Soc. London, Spec. Publ., 393, 277-290, 2015.

Krogh, T. E.: A low-contamination method for hydrothermal decomposition of zircon and extraction of $\mathrm{U}$ and $\mathrm{Pb}$ for isotopic age determinations, Geochim. Cosmochim. Acta, 37, 485-494, 1973.

Larin, A. M., Neymark, L. A., Gorokhovsky, B. M., and Ovchinnikova, G. V: Connection of the complex skarn mineralization of the PitkaĖranta district with the rapakivi granites of the Salmi massif according to $\mathrm{Pb}$ isotope data, Izv. Acad. Nauk. Serya Geol., 5, 47-57, 1990 (in Russian).

Lecumberri-Sanchez, P., Vieira, R., Heinrich, C. A., Pinto, F., and Wälle, M.: Fluid-rock interaction is decisive for the formation of tungsten deposits, Geology, 45, 579-582, 2017.

Li, C., Zhang, R., Ding, X., Ling, M., Fan, W., and Sun, W.: Dating cassiterite using laser ablation ICP-MS, Ore Geol. Rev., 72, 313322, 2016.

Li, Y., Selby, D., Condon, D., and Tapster, S.: Cyclic magmatichydrothermal evolution in porphyry systems: high-precision U$\mathrm{Pb}$ and Re-Os geochronology constraints on the Tibetan Qulong porphyry Cu-Mo deposit, Econ. Geol., 112, 1419-1440, 2017.

Liu, Y., Li, Z., Li, H., Guo, L., Xu, W., Ye, L., Li, C., and Pi, D.: U$\mathrm{Pb}$ geochronology of cassiterite and zircon from the Dulong Sn$\mathrm{Zn}$ deposit: Evidence for Cretaceous large-scale granitic magmatism and mineralization events in southeastern Yunnan province, China, Acta Petrol. Sin., 23, 967-976, 2007.

Ludwig, K.: Isoplot version 4.15: a geochronological toolkit for microsoft Excel, Berkeley Geochronol. Center, Spec. Publ., 4, 247 270, 2008.

Mathur, R., Powell, W., Mason, A., Godfrey, L., Yao, J., and Baker, M. E.: Preparation and Measurement of Cassiterite for Sn Isotope Analysis, Geostand. Geoanal. Res., 41, 701-707, https://doi.org/10.1111/ggr.12174, 2017. 
McNaughton, N. J., Pollard, P. J., Gulson, B. L., and Jones, M. T.: Cassiterite: Potential for direct dating of mineral deposits and a precise age for the Bushveld Complex granites: Comment and Reply, Geology, 21, 285-286, 1993.

Moore, J. M. and Jackson, N.: Structure and mineralization in the Cligga granite stock, Cornwall, J. Geol. Soc. London, 133, 467480, 1977.

Moscati, R. J. and Neymark, L. A.: U-Pb geochronology of tin deposits associated with the Cornubian Batholith of southwest England: Direct dating of cassiterite by in situ LA-ICPMS, Miner. Depos., 55, 1-20, 2019.

Mungall, J. E., Kamo, S. L., and McQuade, S.: U-Pb geochronology documents out-of-sequence emplacement of ultramafic layers in the Bushveld Igneous Complex of South Africa, Nat. Commun., 7, 13385, https://doi.org/10.1038/ncomms13385, 2016.

Neymark, L. A., Holm-Denoma, C. S., and Moscati, R. J.: In situ LA-ICPMS U-Pb dating of cassiterite without a knownage matrix-matched reference material: Examples from worldwide tin deposits spanning the Proterozoic to the Tertiary, Chem. Geol., 483, 410-425, 2018.

Parrish, R. R.: An improved micro-capsule for zircon dissolution in $\mathrm{U}-\mathrm{Pb}$ geochronology, Chem. Geol. Isot. Geosci. Sect., 66, 99102, 1987.

Reid, C., Scrivenor, J. B., and MacAlister, D. A.: The geology of the country near Newquay, HM Stationery Office, 1906.

Rizvanova, N. G., Skublov, S. G., and Cheremazova, E. V: Age of hydrothermal processes in the Central Iberian Zone (Spain) according to U-Pb dating of cassiterite and apatite, J. Mining Institute, 225, 275-283, https://doi.org/10.18454/PMI.2017.3.275, 2017.

Roberts, N. M. W., Drost, K., Horstwood, M. S. A., Condon, D. J., Chew, D., Drake, H., Milodowski, A. E., McLean, N. M., Smye, A. J., Walker, R. J., Haslam, R., Hodson, K., Imber, J., Beaudoin, N., and Lee, J. K.: Laser ablation inductively coupled plasma mass spectrometry (LA-ICP-MS) U-Pb carbonate geochronology: strategies, progress, and limitations, Geochronology, 2, 3361, https://doi.org/10.5194/gchron-2-33-2020, 2020.

Romer, R. L. and Kroner, U.: Phanerozoic tin and tungsten mineralization-tectonic controls on the distribution of enriched protoliths and heat sources for crustal melting, Gondwana Res., 31, 60-95, 2016.

Schärer, U.: The effect of initial230Th disequilibrium on young UPb ages: the Makalu case, Himalaya, Earth Planet. Sci. Lett., 67, 191-204, 1984.

Schmitz, M. D. and Schoene, B.: Derivation of isotope ratios, errors, and error correlations for $\mathrm{U}-\mathrm{Pb}$ geochronology using 205Pb-235U-(233U)-spiked isotope dilution thermal ionization mass spectrometric data, Geochem. Geophy. Geosy., 8, Q08006, https://doi.org/10.1029/2006GC001492, 2007.

Scoates, J. S. and Friedman, R. M.: Precise age of the platiniferous Merensky Reef, Bushveld Complex, South Africa, by the U-Pb zircon chemical abrasion ID-TIMS technique, Econ. Geol., 103, 465-471, 2008.
Scoates, J. S. and Wall, C. J.: Geochronology of Layered Intrusions, in Layered Intrusions, Springer, Dordrecht, 3-74, https://doi.org/10.1007/978-94-017-9652-1_1, 2015.

Sear, L. G.: The fusion of difficult materials including chromite, cassiterite and reduced sulphur, X-Ray Spectrom., 26, 105-110, 1997.

Simons, B., Shail, R. K., and Andersen, J. C. Ø.: The petrogenesis of the Early Permian Variscan granites of the Cornubian Batholith: lower plate post-collisional peraluminous magmatism in the Rhenohercynian Zone of SW England, Lithos, 260, 76-94, 2016.

Smith, M., Banks, D. A., Yardley, B. W. D., and Boyce, A.: Fluid inclusion and stable isotope constraints on the genesis of the Cligga Head Sn-W deposit, SW England, Eur. J. Mineral., 8, 961-974, 1996.

Stacey, J. S. and Kramers, J. D.: Approximation of terrestrial lead isotope evolution by a two-stage model, Earth Planet. Sci. Lett., 26, 207-221, 1975.

Tapster, S., Condon, D. J., Naden, J., Noble, S. R., Petterson, M. G., Roberts, N. M. W., Saunders, A. D., and Smith, D. J.: Rapid thermal rejuvenation of high-crystallinity magma linked to porphyry copper deposit formation; evidence from the Koloula Porphyry Prospect, Solomon Islands, Earth Planet. Sci. Lett., 442, 206-217, 2016.

Vermeesch, P.: IsoplotR: A free and open toolbox for geochronology, Geosci. Front., 9, 1479-1493, 2018.

Wayne, D. M., Miller, M. F., Scrivener, R. C., and Banks, D. A.: U-Pb and $\mathrm{Rb}-\mathrm{Sr}$ isotopic systematics of fluids associated with mineralization of the Dartmoor granite, southwest England, Geochim. Cosmochim. Acta, 60, 653-666, 1996.

Yamazaki, E., Yokyama, T., Ishihara, S., and Tang, H.: Tin isotope analysis of cassiterites from Southeastern and Eastern Asia, Geochem. J., 47, 21-35, 2013.

Yuan, S., Peng, J., Hu, R., Li, H., Shen, N., and Zhang, D.: A precise $\mathrm{U}-\mathrm{Pb}$ age on cassiterite from the Xianghualing tin-polymetallic deposit (Hunan, South China), Miner. Depos., 43, 375-382, 2008.

Yuan, S., Peng, J., Hao, S., Li, H., Geng, J., and Zhang, D.: In situ LA-MC-ICP-MS and ID-TIMS U-Pb geochronology of cassiterite in the giant Furong tin deposit, Hunan Province, South China: New constraints on the timing of tin-polymetallic mineralization, Ore Geol. Rev., 43, 235-242, 2011.

Zeh, A., Ovtcharova, M., Wilson, A. H., and Schaltegger, U.: The Bushveld Complex was emplaced and cooled in less than one million years-results of zirconology, and geotectonic implications, Earth Planet. Sci. Lett., 418, 103-114, 2015.

Zhang, R., Lu, J., Lehmann, B., Li, C., Li, G., Zhang, L., Guo, J., and Sun, W.: Combined zircon and cassiterite $\mathrm{U}-\mathrm{Pb}$ dating of the Piaotang granite-related tungsten-tin deposit, southern Jiangxi tungsten district, China, Ore Geol. Rev., 82, 268-284, 2017. 